\title{
Prevascularized Micro-/Nano-Sized Spheroid/Bead Aggregates for Vascular Tissue Engineering
}

Cite as

Nano-Micro Lett.

(2021) 13:182

Received: 26 June 2021

Accepted: 13 July 2021

Published online: 18 August 2021

(C) The Author(s) 2021

\author{
Maedeh Rahimnejad ${ }^{1,2}$, Narges Nasrollahi Boroujeni ${ }^{3}$, Sepideh Jahangiri ${ }^{2,4}$, \\ Navid Rabiee ${ }^{5 凶}$, Mohammad Rabiee ${ }^{6}$, Pooyan Makvandi ${ }^{7}$, Omid Akhavan ${ }^{5}$, \\ Rajender S. Varma ${ }^{8}$ 还
}

\section{HIGHLIGHTS}

- The first perspective regarding the application of nano-micro size aggregations on the prevascularizations and biomedicine.

- This perspective provides an in-depth discussion regarding the use of these prevascularized nano-micro size aggregates in biomedicine and regenerative medicine.

\begin{abstract}
Efficient strategies to promote microvascularization in vascular tissue engineering, a central priority in regenerative medicine, are still scarce; nano- and micro-sized aggregates and spheres or beads harboring primitive microvascular beds are promising methods in vascular tissue engineering. Capillaries are the smallest type and in numerous blood vessels, which are distributed densely in cardiovascular system. To mimic this microvascular network, specific cell components and proangiogenic factors are required. Herein, advanced biofabrication methods in microvascular engineering, including extrusion-based and droplet-based bioprinting, Kenzan, and biogripper approaches, are deliberated with emphasis on the newest works in prevascular nano- and micro-sized aggregates and microspheres/microbeads.
\end{abstract}

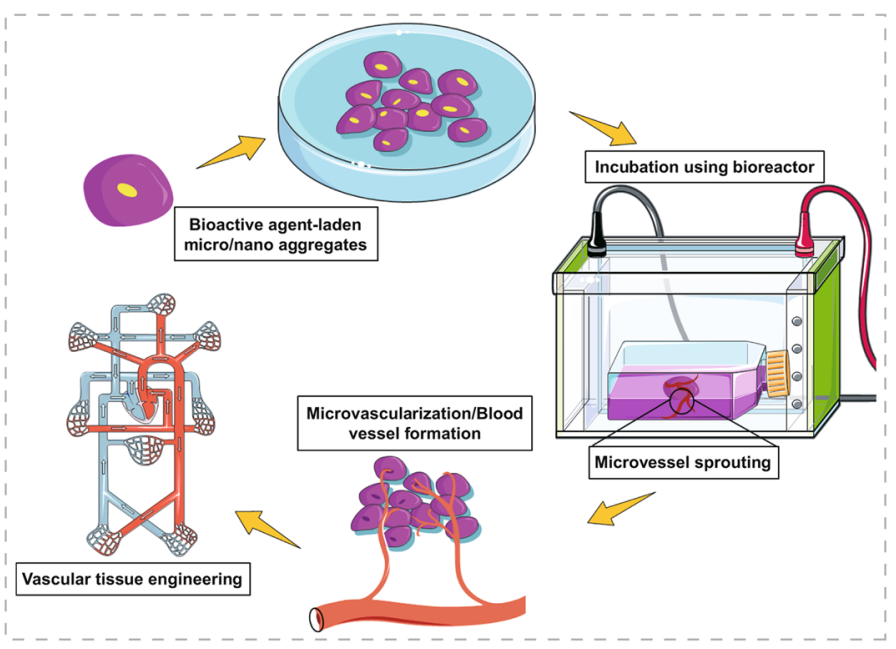

KEYWORDS Vascular tissue engineering; Nano-/micro-sized aggregates; Microspheres

\footnotetext{
Navid Rabiee, nrabiee94@gmail.com; Omid Akhavan, oakhavan@sharif.edu; Rajender S. Varma, varma.rajender@epa.gov

1 Biomedical Engineering Institute, School of Medicine, Université de Montréal, Montreal, Canada

2 Research Centre, Centre Hospitalier de L’Université de Montréal (CRCHUM), Montreal, Canada

3 Department of Industrial Biotechnology, National Institute of Genetics and Biotechnology, Tehran, Iran

4 Department of Biomedical Sciences, Faculty of Medicine, Université de Montréal, Montreal, Canada

5 Department of Physics, Sharif University of Technology, P.O. Box 11155-9161, Tehran, Iran

6 Biomaterial Group, Department of Biomedical Engineering, Amirkabir University of Technology, Tehran, Iran

7 Centre for Materials Interfaces, Istituto Italiano Di Tecnologia, viale Rinaldo Piaggio 34, 56025 Pontedera, Pisa, Italy

8 Regional Centre of Advanced Technologies and Materials, Czech Advanced Technology and Research Institute, Palacky University, Šlechtitelů 27, 78371 Olomouc, Czech Republic
} 


\section{Vascularization}

The biofabrication approach entails building engineered tissues such as vascular networks in the laboratory. In this regard, techniques based on microfluidics technologies and bioprinting can be applied to create vascular networks [1-5]. 3D bioprinting specifically provides a remarkable solution for creating advanced vascularized implants which are difficult to attain via conventional fabrication methods [6-10]. Although these processes have made significant progress, they are not essentially precise and spatiotemporally controllable to simulate the function and physiological complications of the three-dimensional vascular networks [11-13]. In addition to fabrication technique, the most commonly deployed procedure to induce vascularization is the controllable delivery of biomaterials such as hydrogel scaffolds within proangiogenic factors like vascular endothelial growth factor (VEGF) [14-17]. Another approach is cell-based tissue engineering, which have different physicochemical parameters that should be optimized; however, in a specific case, this approach could lead to increasing the cellular density in an specialized organ (Fig. 1) [18].

To engineer vascular tissue, comprehensive understanding of the cardiovascular system is required where capillaries as the smallest type and most numerous blood vessels are distributed densely. They are specialized for regulation of the filtration process to directly exchange nutrients and wastes within tissues which are restricted to $100-200 \mu \mathrm{m}$ [20-23]. Therefore, engineered tissues that are larger in width or length than these dimensions require innate microvascularization for adequate oxygen and nutrients diffusion and survival in vivo [24-26]. Significant impairments in vascularized tissues, for instance bone defects that

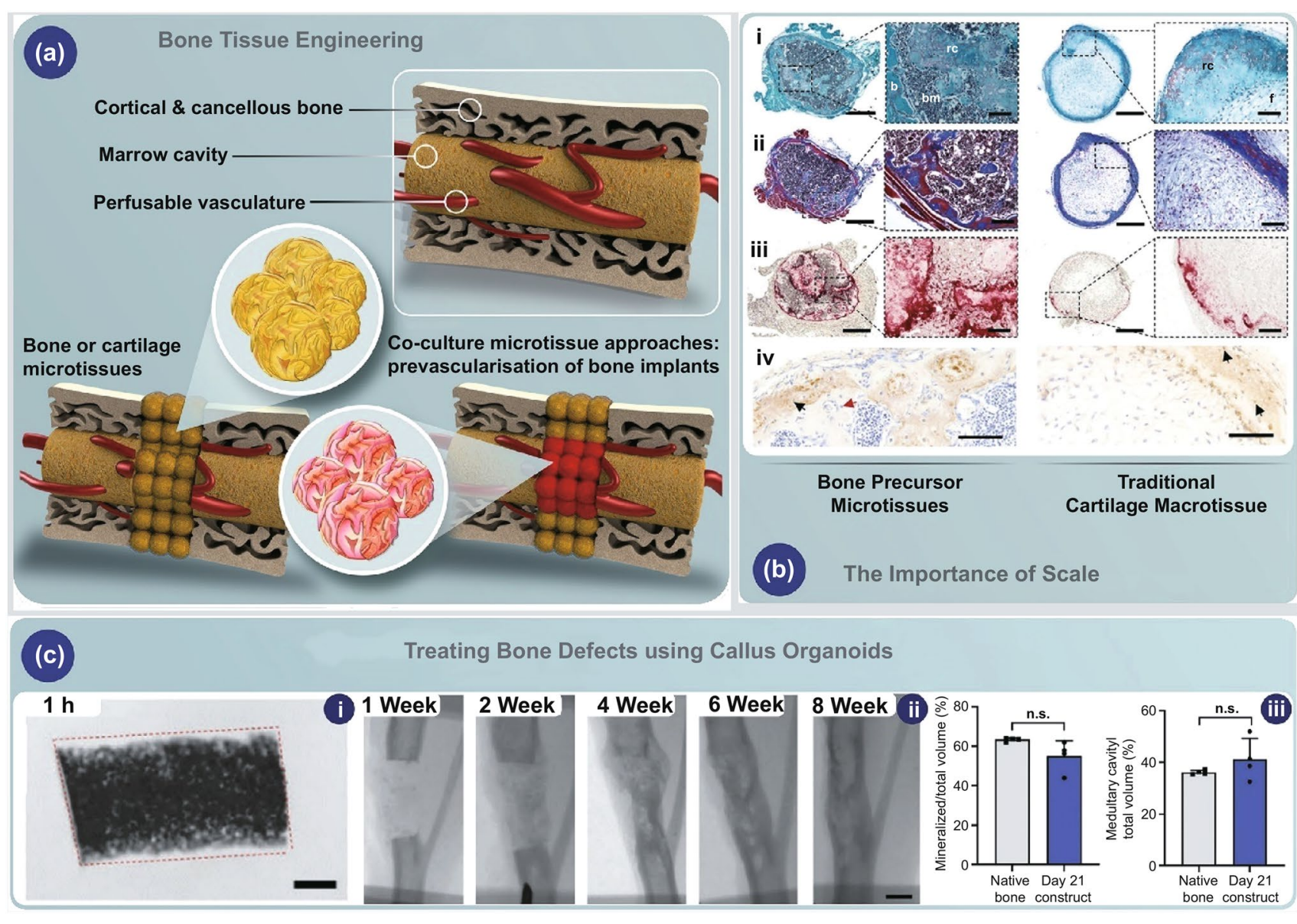

Fig. 1 a Schematic representation of microtissues in bone tissue engineering. b The importance of scale in cartilage precursors for endochondral bone tissue engineering. c The same precursor microtissues can be used to heal a murine, critically sized long bone defect. The figure reprinted $[18,19]$ with permission from Elsevier and Wiley 
do not fully heal on their own, are termed critically sized, so physiological regeneration does not occur naturally as a consequence of normal processes eventually leading to chronic pains affecting millions of people throughout the world [27-29]. The limited characteristic healing capacity of large vascular defects and the limitations of current interventions make their treatments a crucial challenge in clinical settings which need to be addressed [22, 27, 28]. The structure of blood vessels is distinct for each of them [30, 31]. Large vessels including arteries and veins are composed of three main microscopic wall layers: an outer layer made up of collagen fibers and elastic tissue, a middle layer encompassing collagen fibers, elastic tissue and smooth muscle, and an inner layer comprising endothelium [32-34]. Arteries contain more percentage of elastic tissue than veins that enables them to enhance their blood conduction capacity as the blood pressure increases [35]. Small vessels including venules arterioles and capillaries have much thinner and narrower walls in proportion to arteries and veins. Venules and arterioles are small diameter blood vessels composed of thin layers of fibrous tissue and smooth muscle, respectively [36-38]. The smallest vessels in the body are capillaries which are normally only one cell in thickness allowing optimal mass exchange and fluid permeability. The cell types vary slightly according to vessel size. Veins, arteries and arterioles consist of endothelial cells (ECs), pericytes and smooth muscle cells (SMCs) [39, 40]. Venules are constituted of endothelial cells (ECs), pericytes and smooth muscle cells (SMCs) which imparts distinguishing characteristics to venules from arteries [41]. Capillaries are made up of single endothelial cells (ECs) and some pericytes which are primarily considered to be cells that stabilize the vessel wall [42]. The main role of large vessels is returning the blood and mass transport toward or away from organs. On the contrary, the small vessels or distinct capillaries are associated with several biological procedures, which include facilitating the transport and absorption of interstitial fluid from the tissues, the migration of lymphocytes, and immune response, etc. [43-45]. Blood vessels function and structures demonstrate their significant complexity. The intricacy of engineering microvasculature is the major challenge in the field of tissue engineering [26, 46, 47]. Also, the key factors for any tissue engineering should be considered as well that includes chemical growth factors [48], stem cells [49], scaffold materials [50], mechanical forces [51], topography of scaffolds [52], electrical stimulation [53], biocompatibility/ biodegradability [54], electro-active scaffolds [55] as well as the cell sheet scaffolds [56] (Fig. 2) [57].

\subsection{Growth Factors}

The extracellular matrix (ECM) is a highly dynamic microenvironment that regulates multiple cellular processes to operate mainly by recruitment and activation of different growth factors (GFs). Varying affinities in different locations lead to diverse GF-ECM interactions; also, there are lots of interconnected interactions to the GFs and its ability to have fully functional behavior (Fig. 3) [58-60]. The ECM regulates downstream signaling pathways by GF activity which binds to cellular receptors and leads to the de novo formation of new vessels during angiogenic process. Many in vitro methods have been established to simulate the sprouting through the controllable release of growth factors from biomaterials. In general, deployed growth factors that stimulate the formation of new blood vessels to subtend basic fibroblast growth factor (BFGF), vascular endothelial growth factor (VEGF), platelet-derived growth factor (PDGF), and transforming growth factor- $\beta$ (TGF- $\beta$ ) [61-64]. Chemical and biological covalent binding reactions can be used to incorporate GFs into matrices or load them into micro-sized aggregates or microspheres for long-term delivery [65-67]. Recently, scientists developed an injectable combination of VEGF-loaded dextran microparticles into poly(lactic-co-glycolic acid) (PLGA) microspheres providing controlled release of GF. The system showed endothelial cells proliferations in vitro and formation of capillaries as well as smooth muscle $\alpha$-actin-positive vessels in vivo when injected to the rat ischemic tissue [68]. In another study, microfluidic technology was used to create PLGA microspheres consisting of anhydrous reverse micelle (R.M.) dipalmitoylphosphatidylcholine (DPPC) nanoparticles which was loaded with VEGF; slow and sustained release over 28 days was reported resulting in promoted proliferation of human umbilical vein endothelial cells [69]. Similarly, Tayebi research team fabricated PLGA microspheres with average sized of $16-36 \mu \mathrm{m}$ for controlled release of VEGF [70]. A recent effort reviewed the potential and applications of various micro-sized particles for controlled and sustained GF release [71].

Growth factors can be released only upon a local cellular demand by using various physical stimuli sources that 


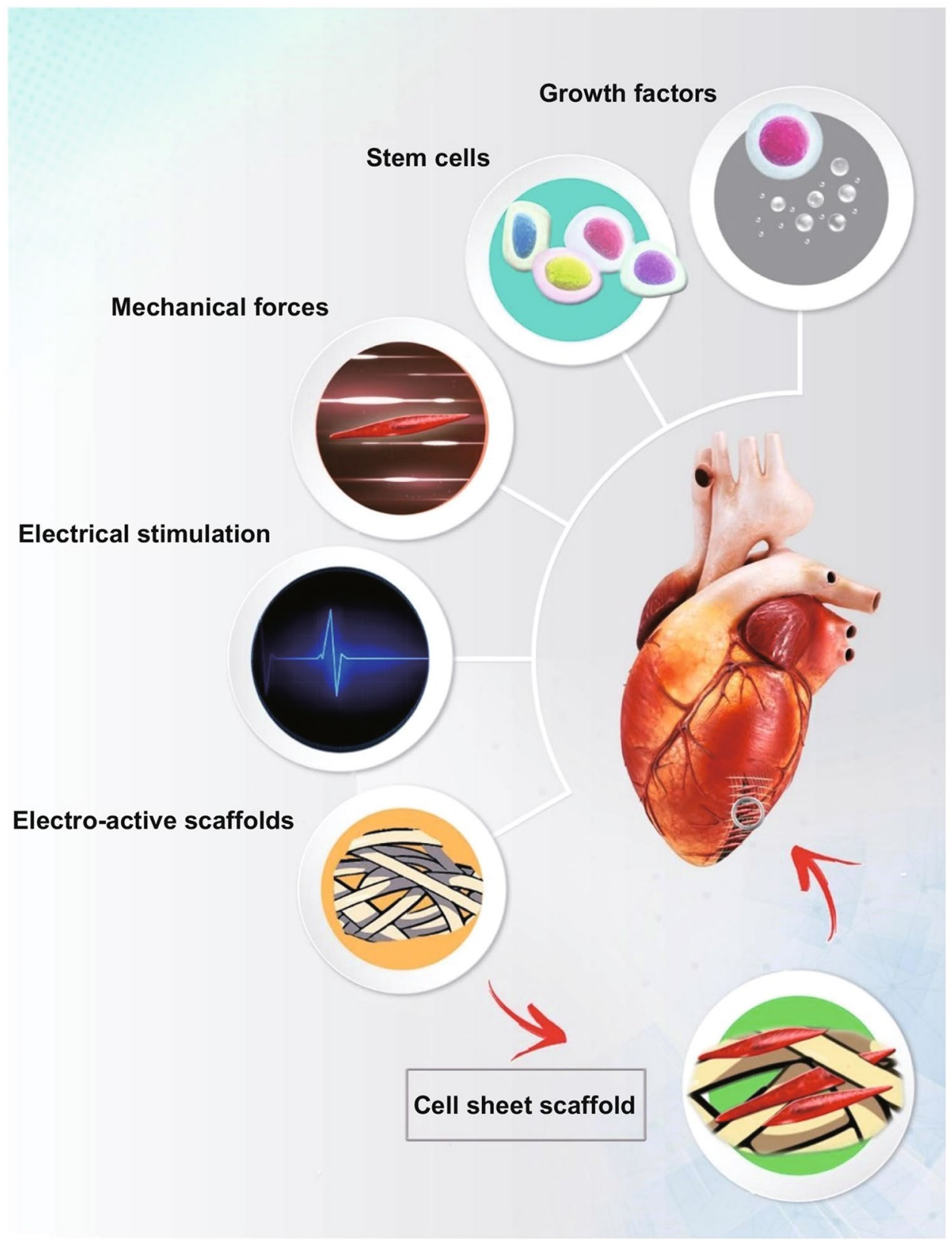

Fig. 2 Key factors involved in the cardiac tissue engineering [57]

are insignificantly invasive such as light, ultrasound and localized heat [72-76]. For an example, magneto-thermoresponsive smart carrier has been developed using poly $(\mathrm{N}-$ isopropylacrylamide) (PNIPAM) to control the release and absorption of VEGF, stimulating human umbilical vein endothelial cells proliferation [77]. Perceptual presentation and gentle release of growth factors has a crucial function in modulating neovascularization $[78,79]$. Sprouting of vessels and endothelial cells migration in a specific orientations can be performed by applying light leading to modeling of growth factors, which could lead to a homogenous and aligned patterns of VEGF onto an specific substrate (Fig. 4), and also resulted in high-resolution cellular culturing in the presence of photopatterned VEGFs on the surface of the substrate (Fig. 5) [80, 81]. It has been shown that spatial GF gradient can be removed by interstitial flow with time, which 


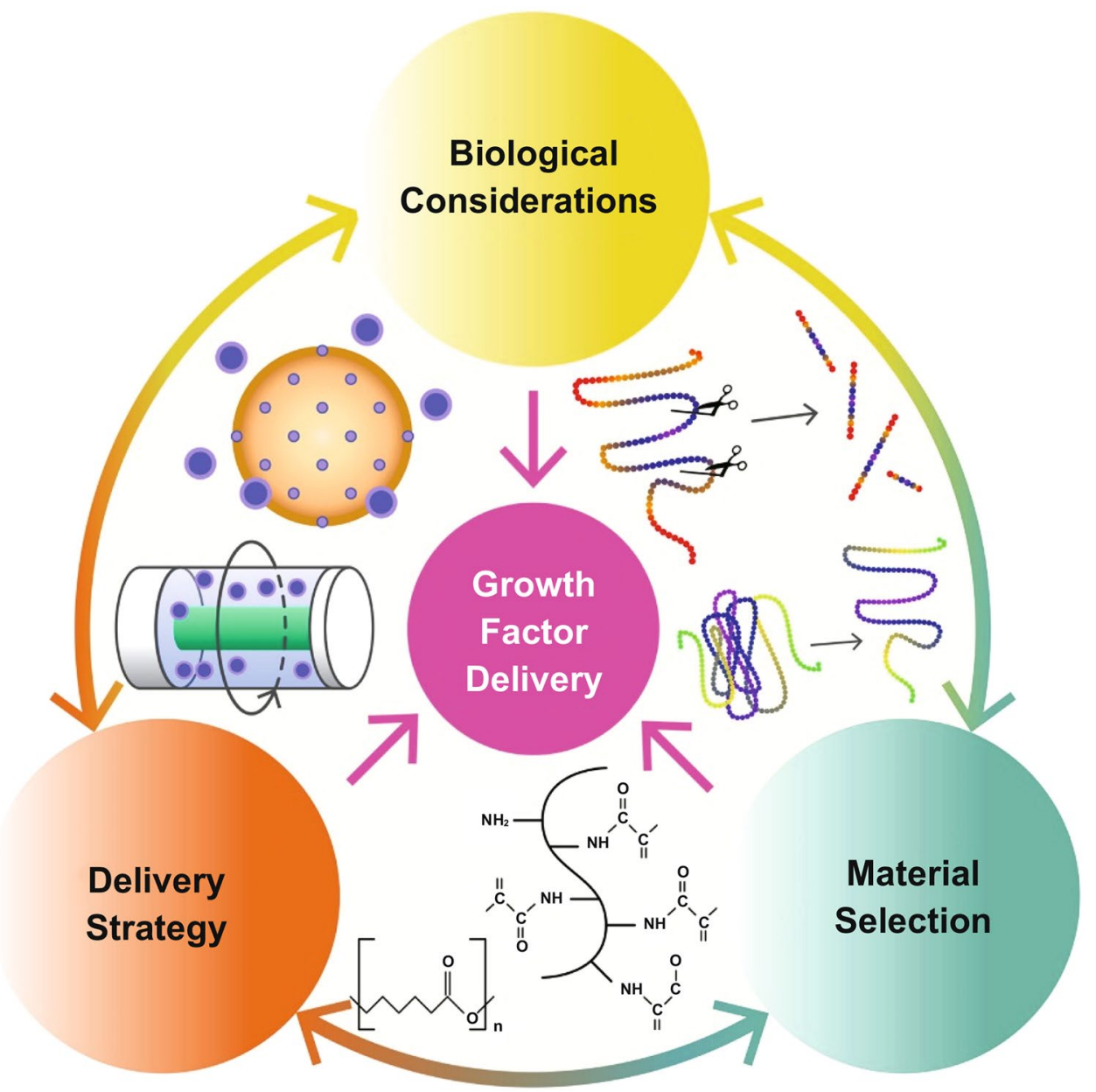

Fig. 3 A schematic illustration regarding the delivery of GFs and effect of each key factors on this delivery system [15]

indicates that growth factors and fluid forces collaborate to control the growth of new blood vessels [82].

Another strategy to model vascularization is via release of proangiogenic paracrine factors by engineering cells function. For instance, scientists demonstrated that incorporation of gelatin microspheres within vascular tissue rings promotes GF release and expression of smooth muscle contractile protein through cellular self-assembly [83]. It has been demonstrated that arteriogenic gene expression profiles are enhanced by preconditioning mesenchymal progenitor cells secreting TGF- $\beta$ in low concentrations. The secretion of stromal cell-derived factor 1 reportedly promotes the vascular formation when mesenchymal progenitor cells are cultured in infarcted hearts in a myocardial infarction rat model [84]. It has been shown that high-level expression of endogenous VEGF by targeted genetic manipulation of Mesenchymal stem cells (MSCs) significantly improved the angiogenic-supportive capabilities in vivo [85]. An injectable polyethylene glycol-based microbeads modified with VEGF to promote in vivo vascularization resulted in intra-islet engraftment and glucose level regulation [86]. The effective microvascular function is dependent on the fabrication of microvascular mediated with GFs. The lack of these approaches often leads to an out-of-control network organization and the formation of leaky microvessels [87]. Also, another study showed that for skeletal muscle, after culturing the appropriate cells ( $\mathrm{C} 2 \mathrm{C} 12$ cells) on the growth medium for three days, the culture medium successfully exchanged with myoblast medium, which allows stimulations of cell differentiations as well as the cell alignments. After six days, the procedure was completed and fully cell alignments were observed. An interesting point is about the cells grew on the 

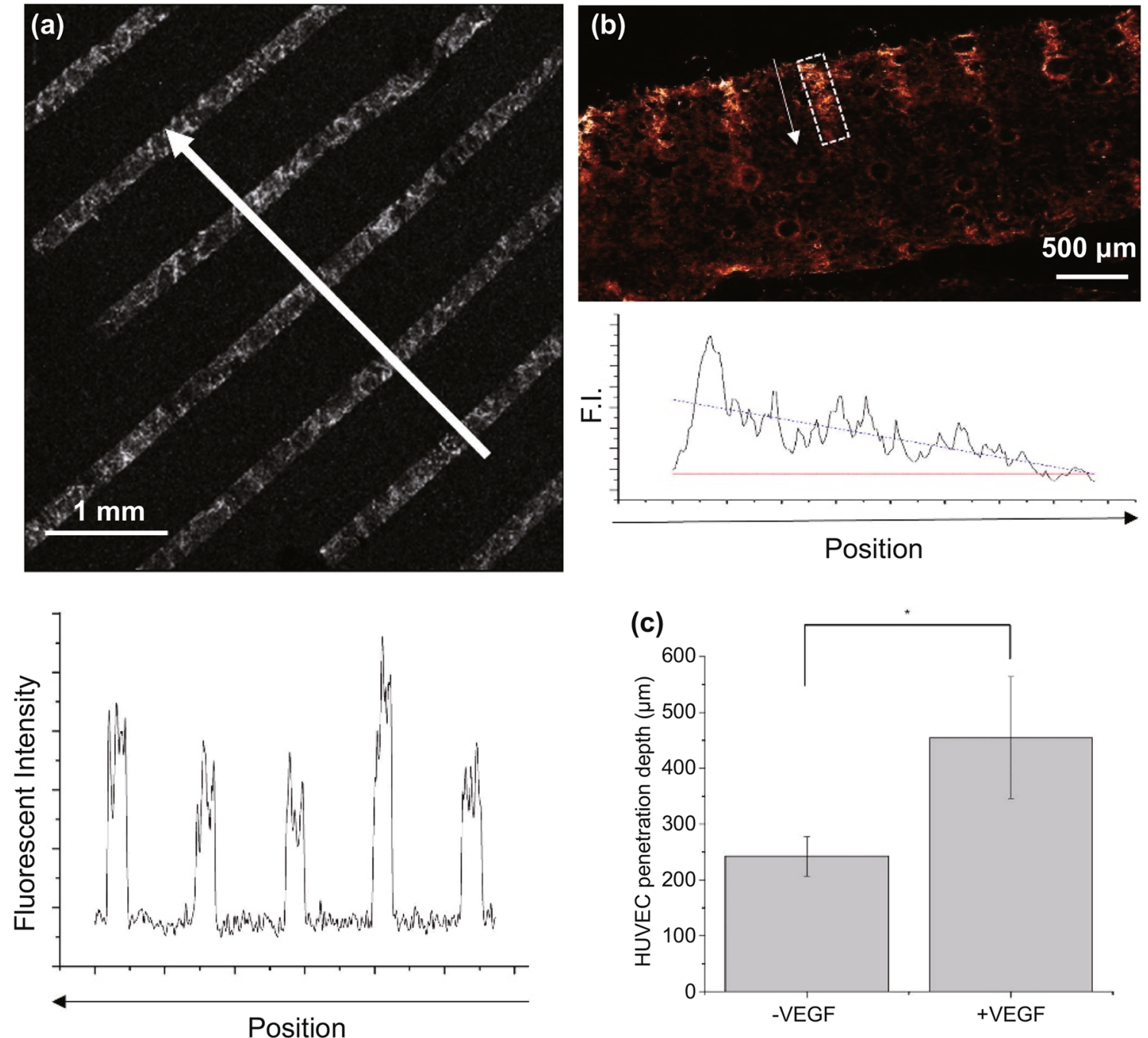

Fig. 4 Photopatterning of VEGF onto the surface of collagen-glycosaminoglycan scaffolds; a the surface of the collagen-glycosaminoglycan scaffolds photopatterned with VEGFs, $\mathbf{b}$ cross-sectional microscopy of the photopatterned VEGF onto the surface of collagen-glycosaminoglycan scaffolds, $\mathbf{c}$ the VEGF bounded amount onto the surface of collagen-glycosaminoglycan scaffolds [80]

leaf-derived cellulose scaffolds, which showed fully alignments; however, on the glass coverslips showed partially alignments in some cases (Fig. 6) [88].

\subsection{Cell Components}

In many bioengineering strategies, researchers have resorted exploiting primary endothelial to fabricate meso- and microscale vasculature [89-91]. Co-bioprinting of human umbilical vein endothelial cells and primary mouse hepatocytes presented promising cell-cell interaction and significantly enhanced the metabolic activity of CYP1A2 and the functionality of hepatocytes due to proper induced vascularization [92]. Bersini et al. reported that their 3D bioprinted human muscle-specific endothelium model is differentiated from primary endothelial cells and is supported by a vascular network [93]. Recently, critical role of endothelial cells in hair growth has been disclosed, in which an aggregate made of human vascular endothelial cells, a human dermal papilla suspension and mouse embryonic epithelial cells was formed, which then localized in hair follicle germs; system improved follicular gene expression leading to hair regeneration [94]. Carmeliet et al. published a single-cell study revealing the transcriptome atlas of endothelial cells that provides a better characterization of endothelial cells 
(a)
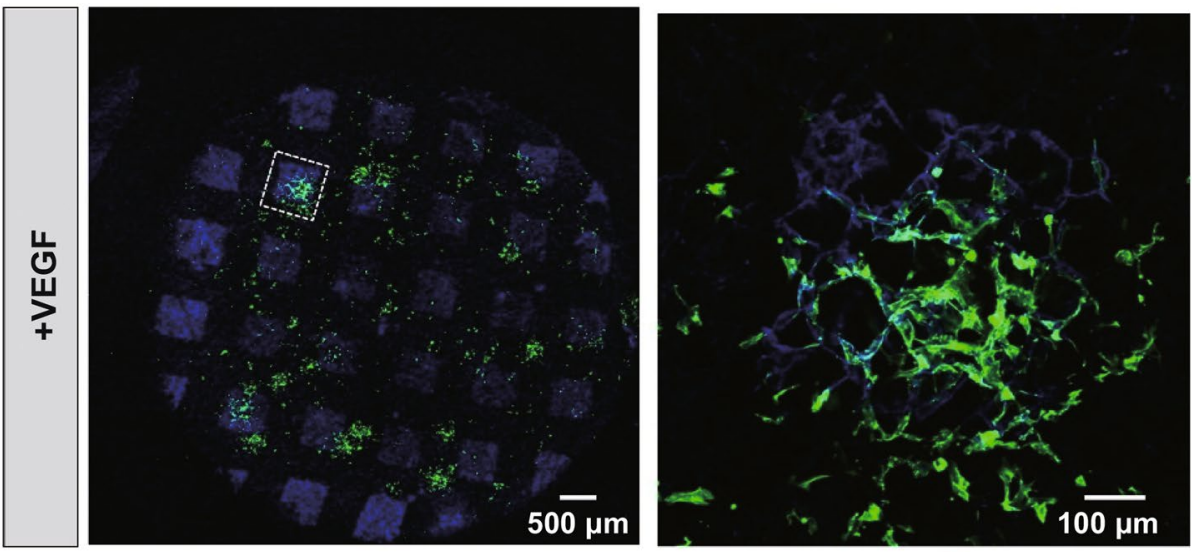

(b)
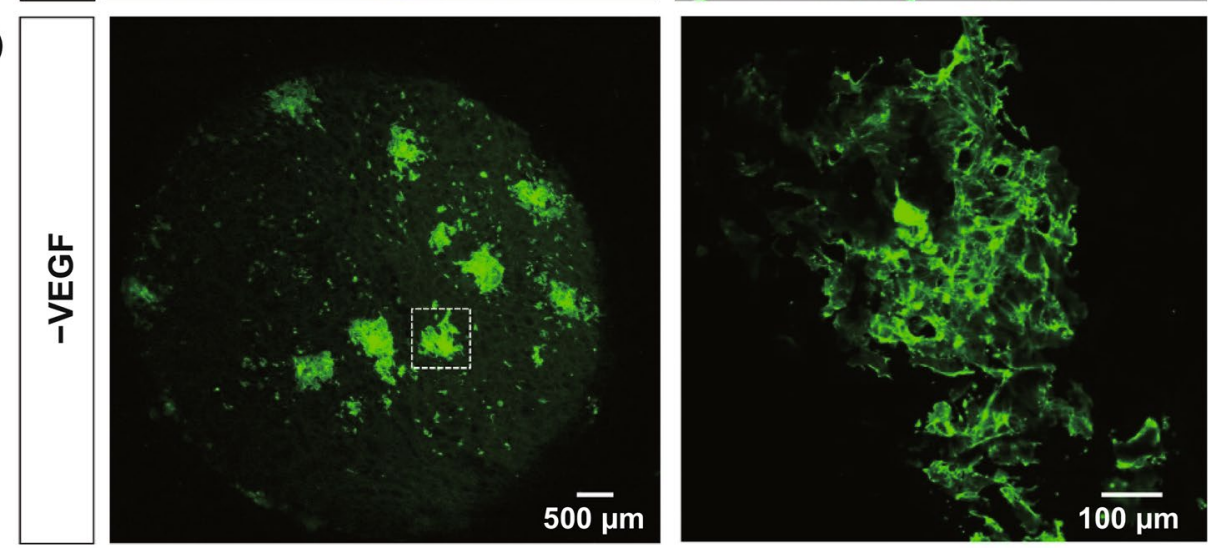

Fig. 5 The photopatterned VEGF onto the surface of collagen-glycosaminoglycan scaffolds, a images of the HUVEC cells cultured on the modified photopatterned scaffolds, and $\mathbf{b}$ cultured on the unmodified photopatterned scaffolds [80]

heterogenicity which may solve the main challenge to simulate the vascular models in micro- and mesoscales, especially in regenerative medicine. This atlas contains the whole transcriptome of endothelial cells in both specialized and unexpected (Fig. 7) endothelial phenotypes. All of these results have been validated by protein-protein investigations as well as the specific protein analysis (Fig. 8), which could help the scientists to evaluate the behavior and interaction of the nanomaterials and their interconnected relationships inside the cellular microenvironments [95].

There is a critical role for pericytes in autocrine and paracrine signaling to affect the microvasculature. Besides, the capillary formation and regeneration is regulated by pericyte abundance, specification and plasticity [96]. Some challenges have been encountered in recapitulating these cells in vitro; neural-glial antigen 2 , smooth muscle actin and platelet-derived growth factor receptor-beta are surface markers expressing in different varieties that can create a potential to be differentiated into smooth muscle cell and other stromal cell types [97]. Perivascular cells have the potential to trigger the factors impacting to supply some of the supportive scaffolding for angiogenic sprouting formation in microvascular models, although they lack the tissuespecific hallmarks of pericytes. Consequently, perivascular cell replacement as a critical bioengineering approach involves differentiating stem cells (i.e., bone marrow or primary fibroblasts-derived MSCs) in engineered models [98-101]. For example, researchers reported human-derived MSCs and endothelial cells interaction under controlled perfusion circumstances provided by microfluidic device which has resulted in promotion of MSCs proliferation, and proper response of the vascular cells [102]. Composite microbeads fabricated by fibrin and collagen embedded with human fibroblasts and endothelial cells showed pericyte-like function, and deposition of laminin that is indicated in the microvessel network maturation over 14 days in vitro culture and formation of prevascularized microtissue [103]. In another study, collagen microspheres have been loaded with 

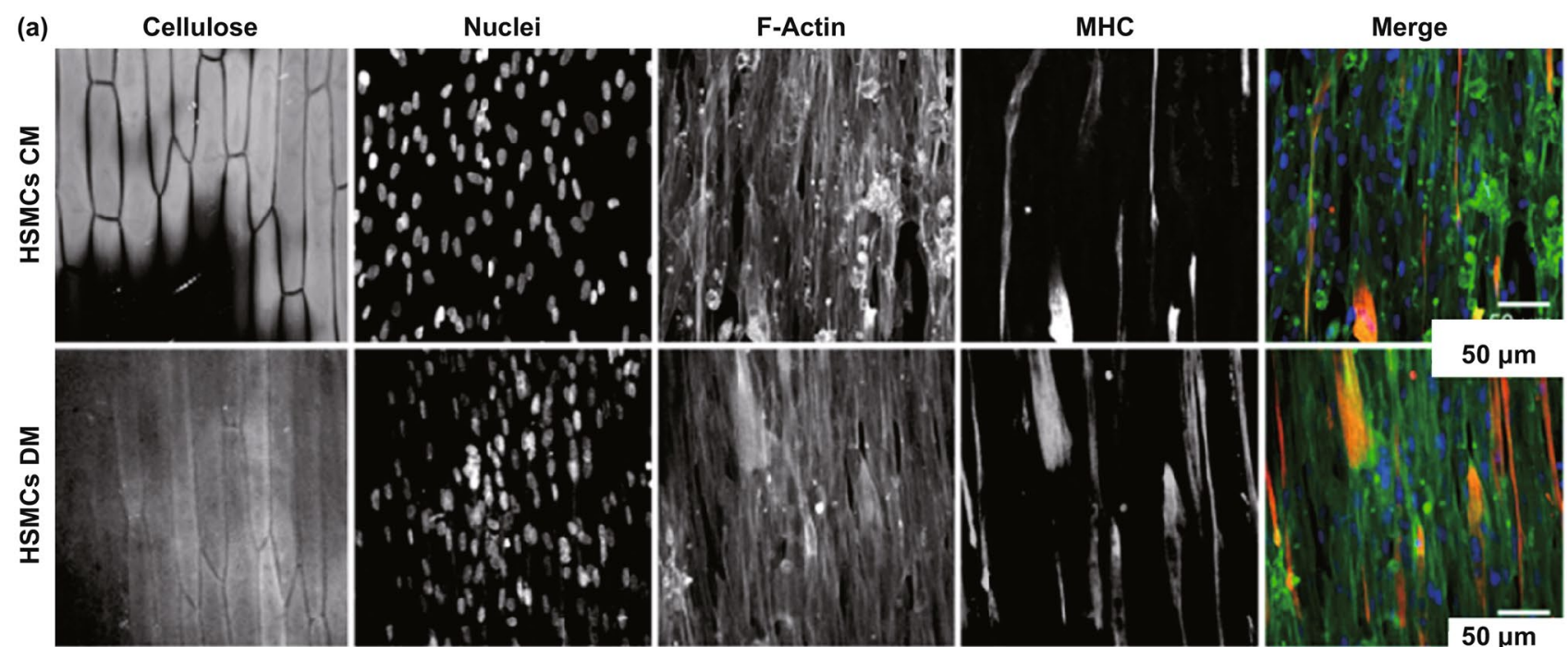

(b)

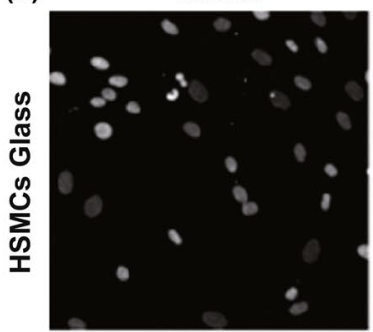

F-Actin

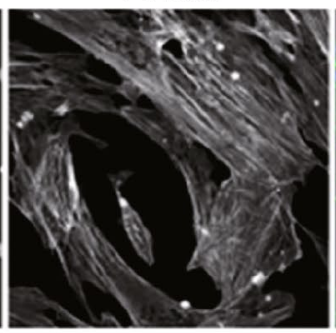

Merge

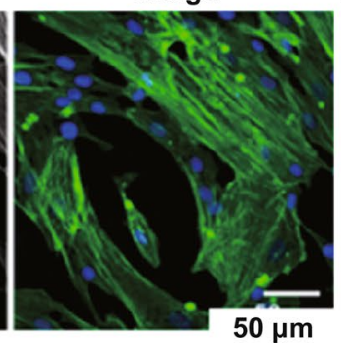

(c)

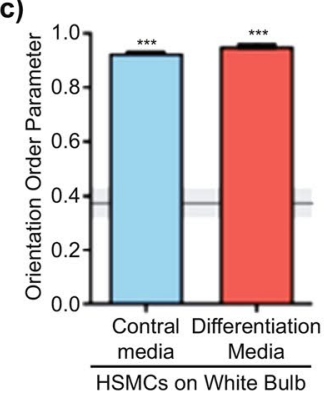

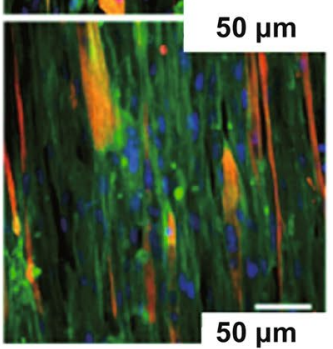

(d)

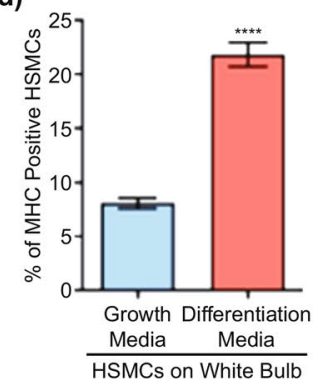

Fig. $6 \mathrm{C} 2 \mathrm{C} 12$ cells differentiate into aligned myotubes when cultured on the outer surface of the green onion derived cellulose scaffolds. a When cultured on the outer green onion white bulb or green leaf cellulose scaffolds. b Example confocal fluorescence image showing $\mathrm{C} 2 \mathrm{C} 12$ cells align randomly when cultured on a fibronectin-coated $\left(50 \mu \mathrm{g} \mathrm{mL}^{-1}\right)$ glass coverslip. c Quantitative analysis of the fluorescence images obtained for actin alignment is performed via a $2 \mathrm{D}$ orientation order parameter (OOP) of $\mathrm{C} 2 \mathrm{C} 12$ cells seeded on various substrates. Reprinted with permission from [88]. Copyright 2021 American Chemical Society

human bone marrow-derived MSCs to stimulate the pluripotent stem cell-derived endothelial cells (iPSC-EC). Herein, due to MSCs interaction with iPSC-EC, they adopted a phenotype of an endothelial cells, expressing CD31 that is the endothelial marker, forming tubular microvessel-like patterns [104].

Employing novel cell sources including iPSC tactics for microvascular tissue engineering or in vivo regeneration have been greatly discerned. The derivative methods of iPSC-human endothelial cells (ECs) (CD144+, CD3 $1+$ antigen expression) generate arterioles or venous-like endothelial populations [105-108]. Compared to HUVEC, some studies have emphasized the lack of endothelial maturation to induce functional deficits after ectopic implantation in the body [89]. A recent study by the Levenberg group indicates the ability of endothelial cells (ECs) which are derived from embryonic stem cell (ESC) to anastomose into native murine tissue, as demonstrated by the first case of human CD31 + blood vessel cells in the lumen [109]. Early work revealed CXCL12/ CXCR4 chemotactic signaling in iPSC-ECs can promote revascularization of the ischemic retina which contributed significantly to vascularization better than human primary endothelial cells [110]. Collagen-based microspheres loaded with human umbilical vein endothelial cells (HUVEC) have been developed and showed remarkable increased of CD31 + suggesting neovascularization after 14 days in vivo implantation (Fig. 9); results have been supported for the first time by multiphoton microscopy with high-resolution spectra (Fig. 10) [111].

Diverse approaches are available to direct differentiation protocols for pericytes and generation of iPSC- and 

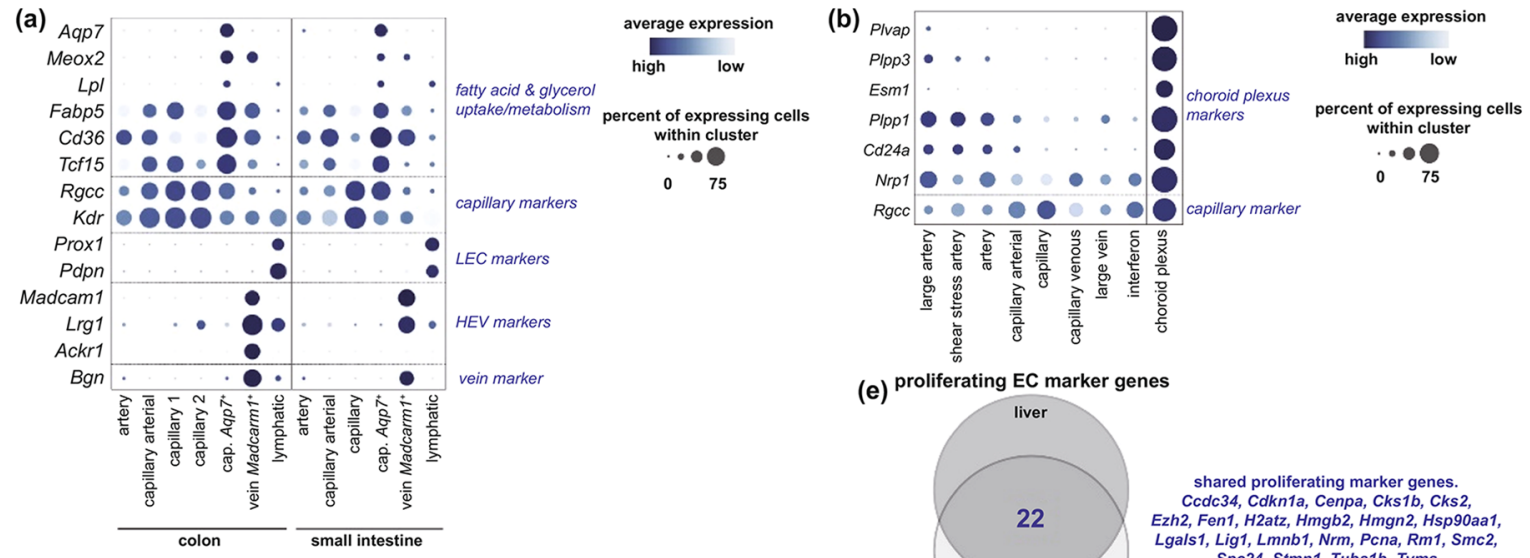

(e) proliferating EC marker genes
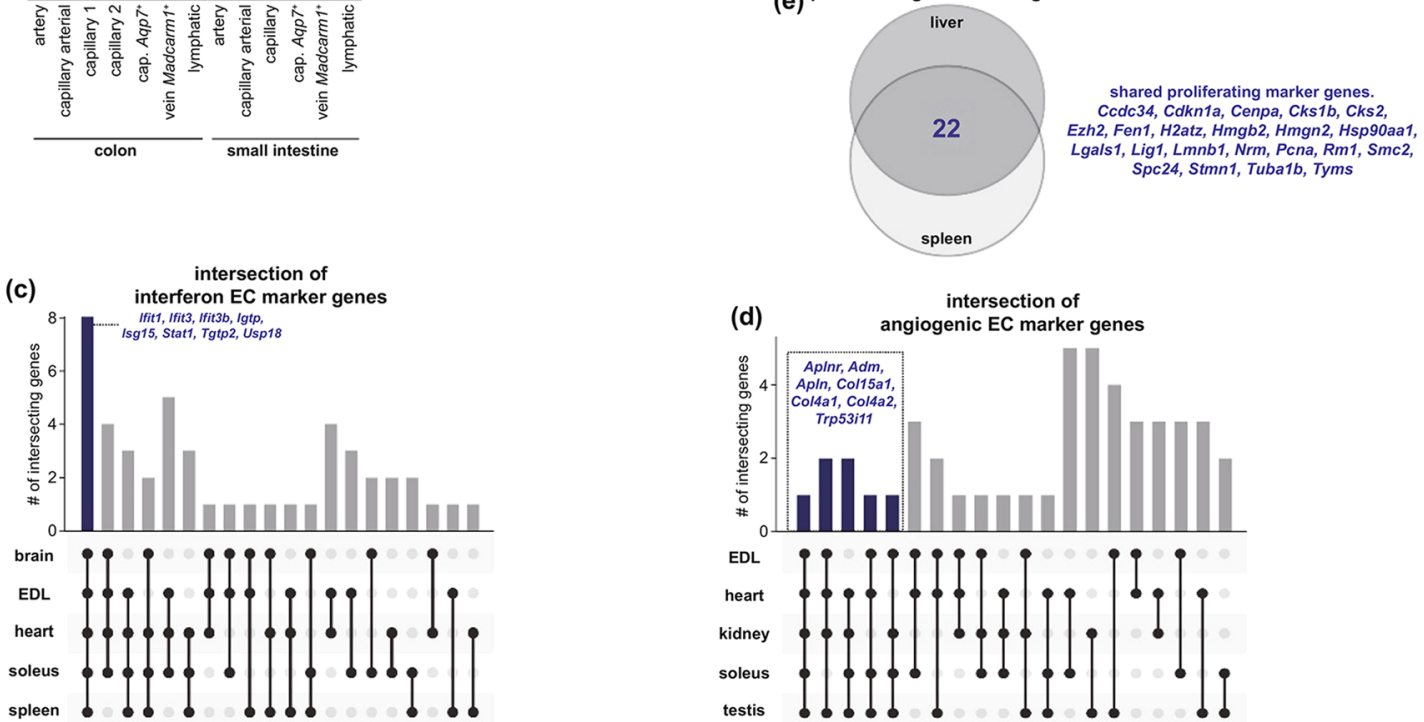

(f)

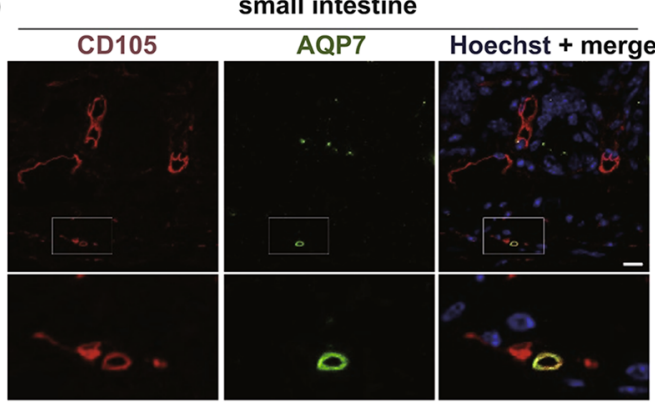

(h)

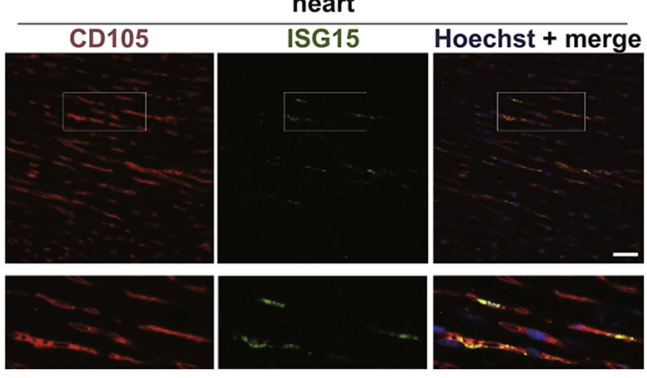

(g)

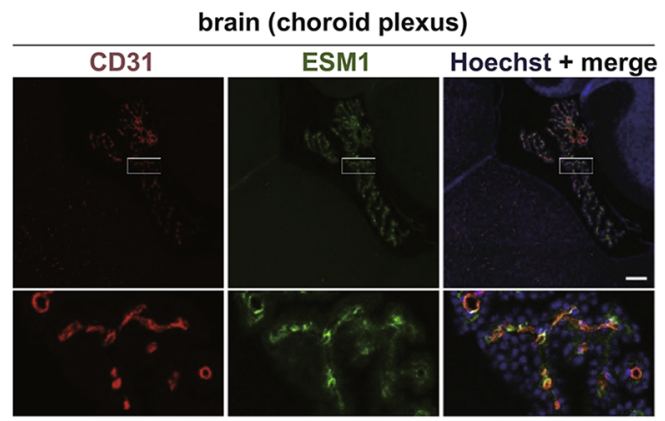

(i)

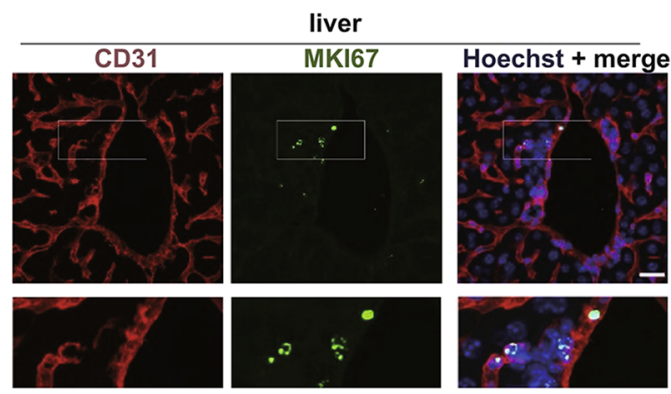

Fig. 7 Specialized and unexpected endothelial cells phenotypes. a, b Dot-plot heatmap of markers enriched in intestinal $A q p 7^{+}$capillary and Madcaml $^{+}$vein ECs. c, d UpSet plot of intersections between the top 50 markers expressed by interferon-activated. e Venn diagram showing genes upregulated in proliferating ECs. $\mathbf{f}-\mathbf{i}$ Representative micrographs of mouse tissue sections. Reprinted from [95] with permission 
(a)
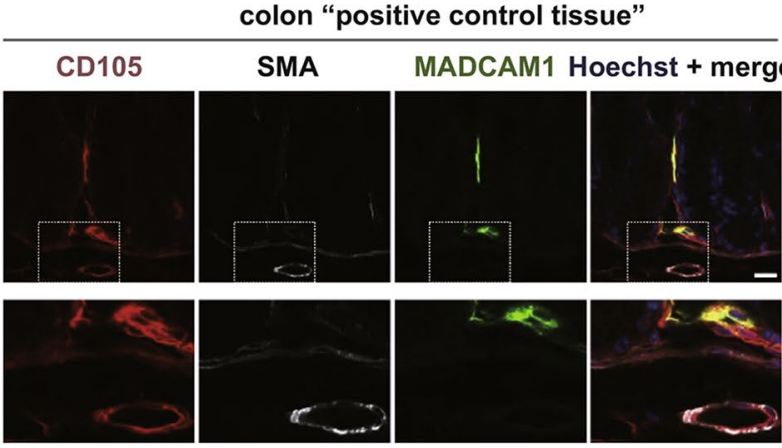

(c)

brain "negative control tissue"
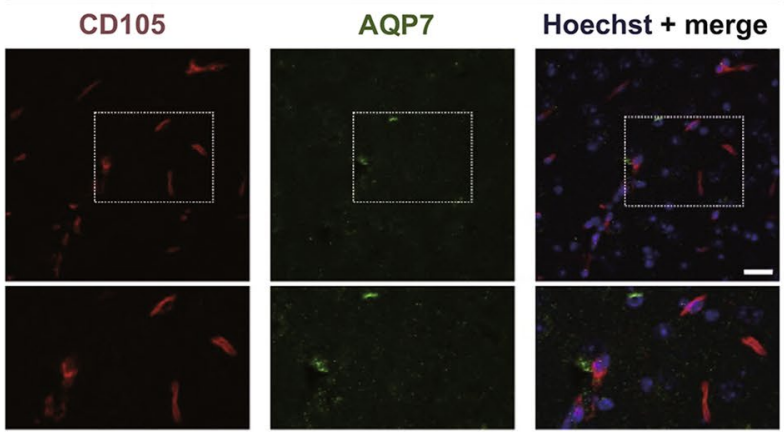

(e)

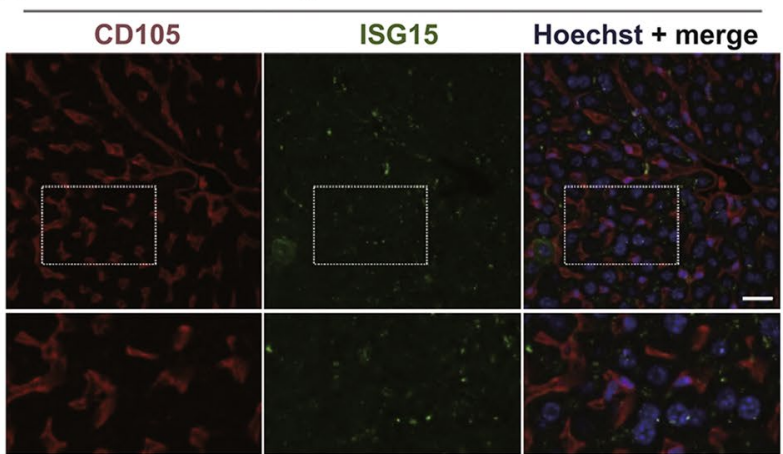

(f)

liver "positive control tissue"

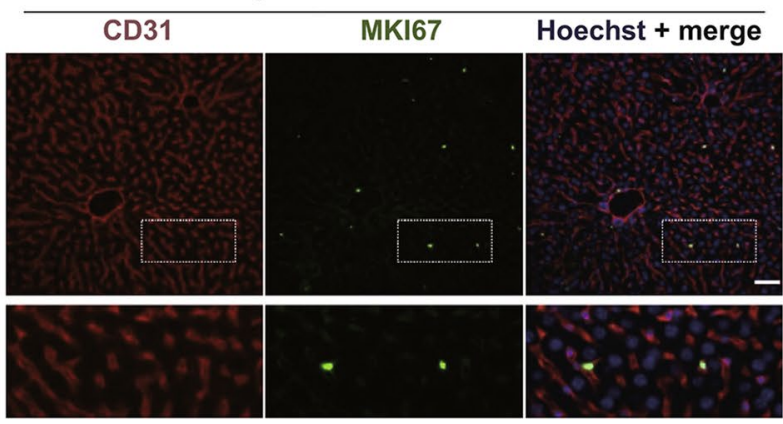

(b) kidney "negative control tissue"

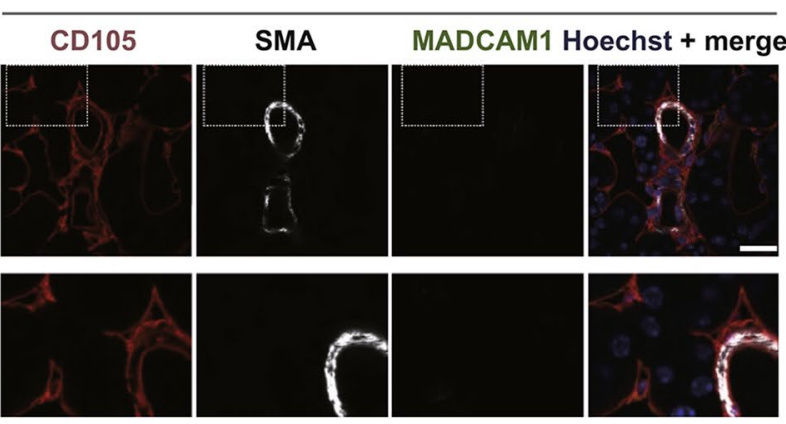

(d)

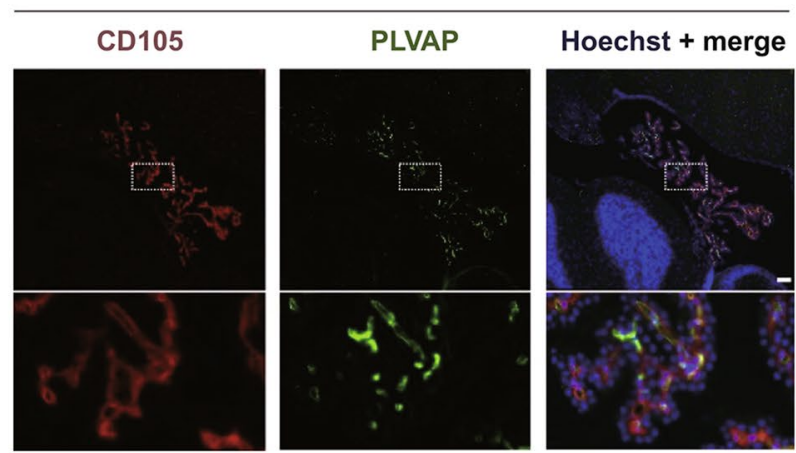

(g)

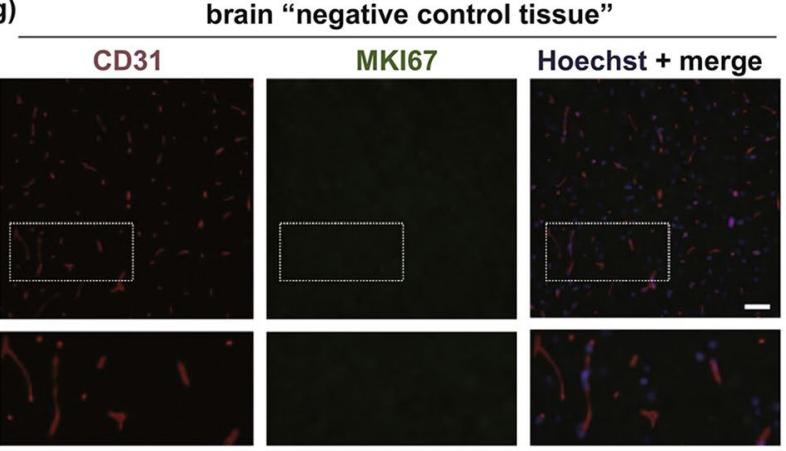

Fig. 8 Protein validation of specialized endothelial cells phenotypes. a, b Representative micrographs of mouse colon. c, $\mathbf{d}$ Representative micrographs of mouse brain sections (negative and positive control group). e-g Representative micrographs of mouse liver (negative and positive control groups) [95] 

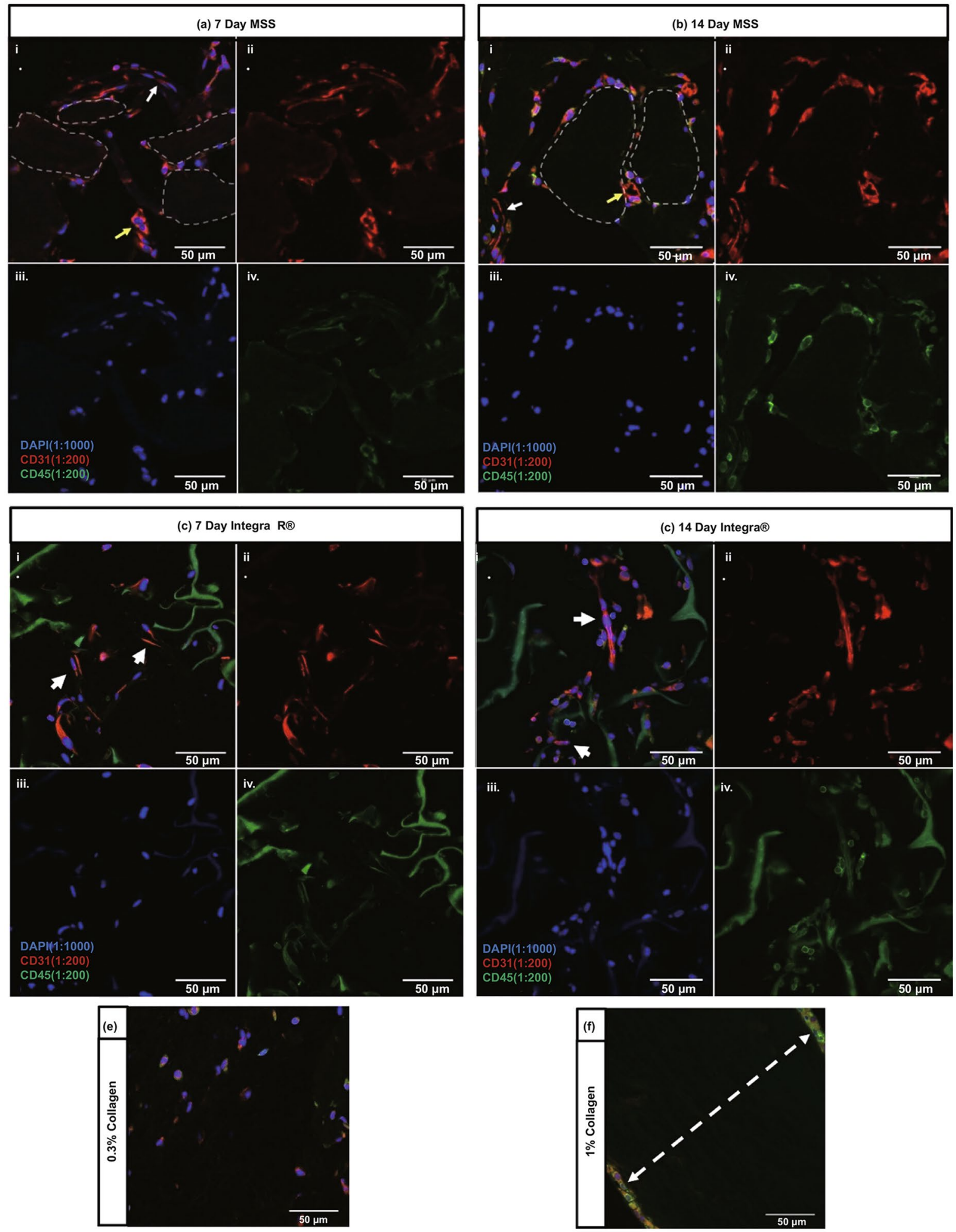

Fig. 9 In vivo phases on the neovascularization's experiments; a CD31 and CD45 stainings of microsphere scaffolds; b endothelial cell stainings of microsphere scaffolds; $\mathbf{c}, \mathbf{d}$ endothelial cell stainings of Integra ${ }^{\circledR}$ scaffolds; e, $\mathbf{f}$ CD31 and CD45 stainings of type I collagen scaffolds [111] 


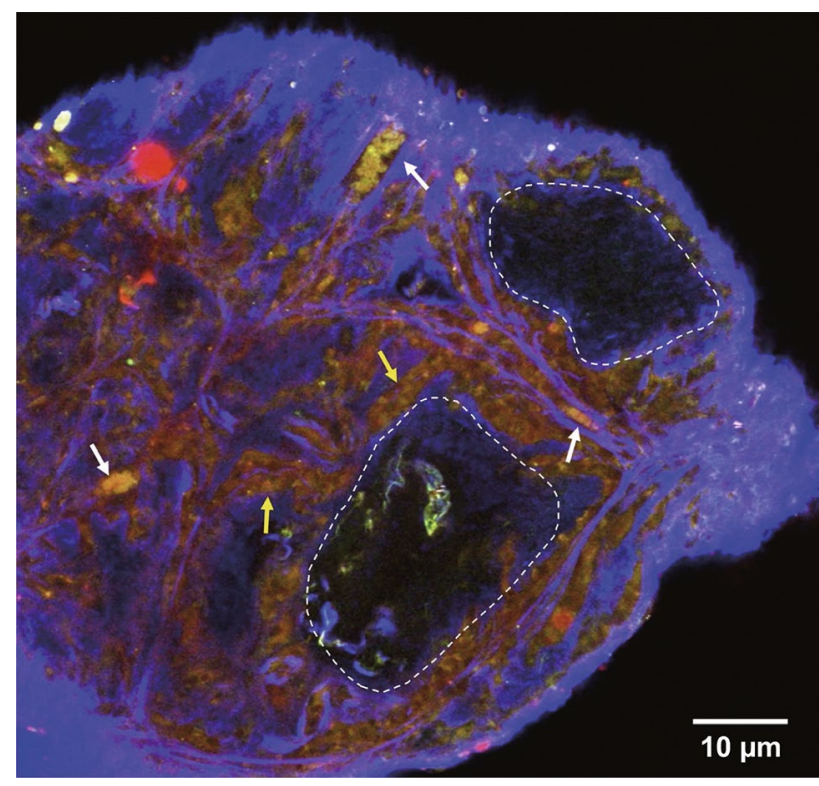

Fig. 10 Multiphoton microscopy of the stained microsphere scaffolds after 14 days [111]

ESC-derived perivascular cells as has been reported by Gerecht and colleagues [112]. ECs, pericytes and vascular smooth muscle cells (VSMCs) can now be generated with high efficiency from human-induced pluripotent stem cells (hiPSC) and used in organ-on-chip development as a fundamental in vitro vascularized model to mimic tissue [113]. In addition to in vitro models, many groups have attempted to obtain functional in vivo implantation in regenerative injury models [114, 115]. The use of iPSCs in engineering meso- and microscale vasculature is an autologous and still unlimited cell source as well as high yield technique affording a most effective tool to generate tissue vascularization and in vitro models.

\section{Gaps and Role of Bioprinting to Address Issues}

Advanced techniques have emerged in microvascular tissue fabrication, including extrusion-based $[116,117]$ and droplet-based bioprinting [118], Kenzan [119], and biogripper approaches $[120,121]$ leading to 3D bioprinting of cellladen aggregates and spheroids.

Extrusion-based bioprinting is a powerful 3D technique that distributes a bioink solution through a nozzle and such bioprinting of cellular aggregates can be used for cell aggregation and tissue strand maturation to generate scalable tissues [122]. As an example, Mao et al. encapsulated human-induced hepatocytes (hiHep cells) within a bioink made up of methacrylated gelatin (GelMA) and liver decellularized extracellular matrix (dECM) to form liver microtissue; significant secretion level of albumin and blood urea nitrogen has been reported indicating excellent liver function [123]. However, most of the printable bioinks comprise similar-sized spheroids suspended in a hydrogel may selfaggregate inside the nozzle during the printing process and therefore clog the needle [124]. The development of organson-chips and micro-physiological systems utilizing extrusion-based bioprinting technology requires highly precise technical details. A comprehensive review on microtissue biofabrication using extrusion-based bioprinting is available [125].

Droplet-based bioprinting (DBB) use a bioink solution to generate biomaterials droplets and cells in high precision. Droplet-based techniques can be further classified into inkjet bioprinting, microvalve bioprinting and acoustic-dropletejection bioprinting [126-129]. Droplet-based bioprinting is appropriate for printing microvasculature for high-resolution patterning in the diameter range of $50-300 \mu \mathrm{m}$ (Fig. 11) [126, 130, 131]; presently, it enables precise positioning of spheroids in 2D, in which spheroids are loaded in a droplet during bioprinting [132]. The formation of the capillary network in the DBB method is based on the self-organization of ECs in printed biological materials. Therefore, the biopaper substrate is an ideal choice for promoting the formation of microvessels after bioprinting. Biological material plays a critical role in microvasculature bioprinting. It is therefore necessary to suppose the proangiogenic properties of both the bioprinting substrate and the bioink; ability of the substrate and bioink unite to promote microvasculature formation. The functional formation of vascular networks depends on rapid self-assembly and high printability structures. Benning et al. introduced an evaluation of commonly used hydrogel bioinks as they demonstrate that fibrin and collagen hydrogels have the potential to provide the necessary support for the human umbilical vein endothelial cells (HUVEC) proliferation in 2D and the capacity to sprout from HUVEC spheroids after 3D printing [133]. The precise spatiotemporal control is presently limited to nano- or picoliters in volume that allows biomaterials, cells, and other biologics deposited in a very precisely controlled manner. In this regard, Boland's group established modified commercial 


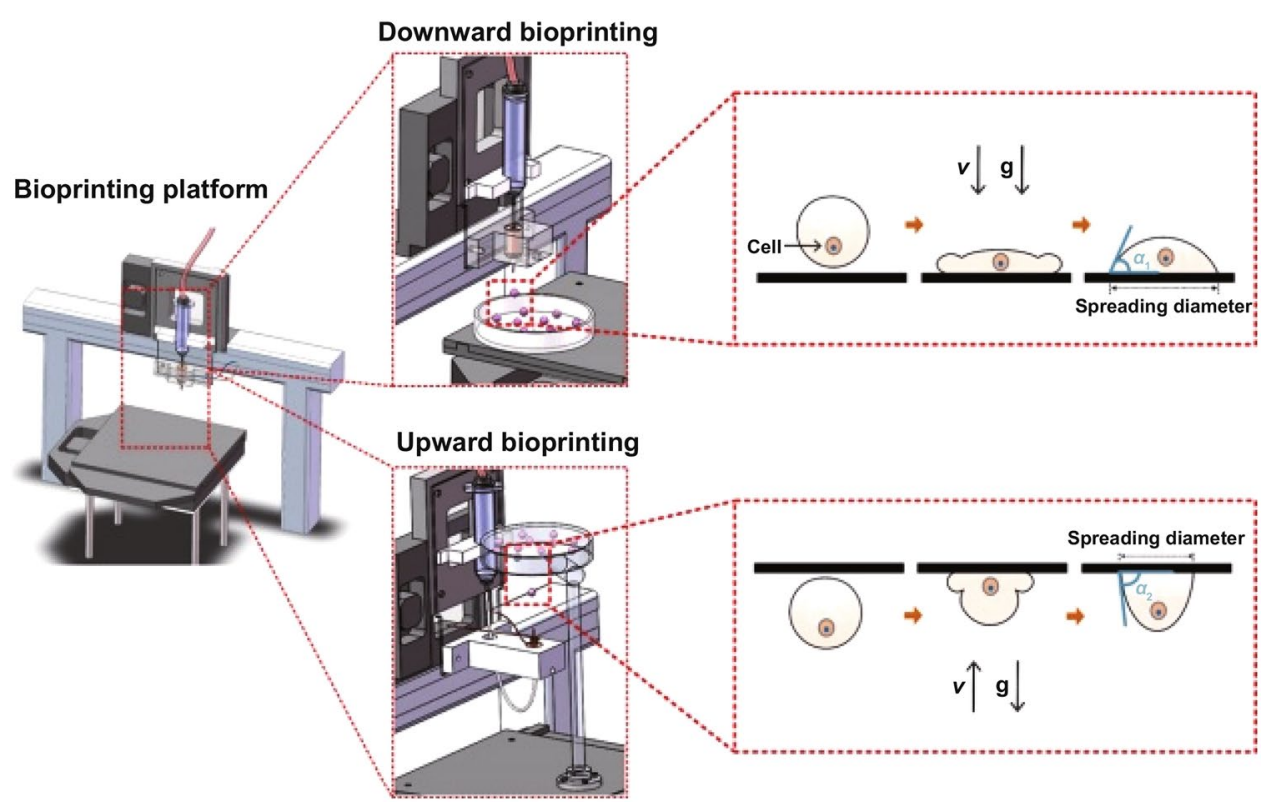

Fig. 11 A schematic illustration of the upward and downward bioprinting devices, as an advanced and high-resolution droplet-based bioprinting systems. Reprinted with permission from [130]. Copyright 2021 American Chemical Society

printing technology for the direct droplet-based bioprinting of microvasculature. The modified inject bioprinter deposited smooth muscle cells and bovine aortic endothelial cells onto collagen and matrigel, respectively [134]. The cell viability was achieved after 3 days of in vitro culture.

Spheroids and microtissues with various biological compositions, e.g., different cells, could not be deposited in arbitrary positions while maintaining spheroids in predetermined positions is challenging. To address this problem, 3D deposition of spheroids and microtissues using microneedles have been introduced [121]. A commercial device capable to bioprint spheroids in a precise way has not been available until the invention of Kenzan method which is a microneedles-based technology launched in Japan [135, 136]. This array of needles bioprint cell-laden spheroids into predesigned contiguous temporary support with micron-level precision [137]. Then, the spheroid-based structure is cultured until the spheroids fuse into cellular aggregates and synthesize their own ECM [138]; spheroids generated using this method have uniform shapes and sizes. During insertion, smaller spheroids have the potential to disintegrate on the needle [137]. To biofabricate microvessels, Kenzan technology has been used, in which human dermal fibroblasts (hDFs) are loaded in spheroids and create tubular structure. Several cells type like vascular endothelial cells and vascular smooth muscle cells migrate into the structure after transplantation of the structure in pigs [139]. Zhang et al. reported study of diaphragm-like patch using Kenzan method. Tubular structure is developed by positioning of $\mathrm{hDFs}$ and hUVECs-laden spheroids. Results of in vivo transplantation in rats showed blood vessels and nerve regeneration [140].

Another technology that has been introduced is biogripper method that is capable of fabricating large perfusable tissue structures through positioning, aligning and manipulating scaffold-free bio-microaggregates with wide range of sizes $(600 \mu \mathrm{m}$ to $3.4 \mathrm{~mm})$ and shapes. The micro-sized aggregates are fragile; therefore, it is highly demanded to keep them in an aqueous environment [141, 142]. Recently, Blanche C Ip et al. introduced a modified and flexible biogripper system with improved optical transparency for the precise alignment of micro-sized aggregates. The force-driven fluid is engineered to deposit aggregates without inducing any damage to the cells [142].

\section{Micro-sized Aggregates and Microspheres/ Microbeads}

Creating a variety of different cell formations including large-scale spheroids [143], honeycombs [141], and strands [144] has been achieved by multiple cell types and co-culture 
of aggregated cells. The ability of extracellular matrix secretion constitutes a significant point for the cells which induce effective communication in a native-like microenvironment [72, 123, 145]. Native-like tissue microenvironment usually is not facilitated due to the limited cell-cell and cell-ECM interactions. It can be attained by the growth of cells in an isolated fashion such as cell-laden hydrogels or cells in monolayers [146]. To address the issue, novel bioprinting technologies have been introduced. Many bioinks formulations including cell aggregates have been reported as a promising tool for bioprinting vascularized tissues. Moreover, its ability for precise placement of high-density cells in the desired location creates a biomimetic construct at a clinically applicable scale. As an example, in a functionalized and high survival of 3D culture model of pancreatic islets, microvascularization is highly demanded. Scheiner et al. employed $50-\mu \mathrm{m}$ poly ( $\varepsilon$-caprolactone-PEG- $\varepsilon$-caprolactone)b-poly(L-lactide) microspheres laden with VEGF in $3 \mathrm{D}$ printed poly(dimethylsiloxane)-based construct and then loaded with the islet cells, which resulted in significant vascularization within 4 weeks [125].

One of the main challenges in vascular tissue engineering involve the lack of cell-cell interactions and microvasculature network sprouting in the cell culture systems which can be addressed by generation of cell-laden spheroids or micro-sized aggregates. Due to the ability of spheroids to fuse, they can be used to form robust endogenous capillary-like networks which can offer new opportunities for creating highly organized vascularized microtissues [147]. In this regard, it has been shown that sprouting of capillary angiogenesis is capable of changing mechanobiological properties of a fibrin cell-laden matrix altering cell fate [148, 149]. In another study, agarose micromolds are used as high yield spheroids with controlled dimensions to develop a platform for high-throughput fabrication of prevascular networks [150]. HUVECs can be successfully differentiated into spheroids and have been recently used in combination with adipose-derived stem cells (ADSCs) to improve the capillary formation within the spheroids in vivo and tissue engineering applications [151, 152]. The laser-induced forward transfer (LIFT) process is a prospective digital printing technique that utilizes hydrogels with a viscosity ranging from 1 to $300 \mathrm{mPa}$ s to promote droplet formation which may lead to a higher cell density (up to 60 million cells $\mathrm{mL}^{-1}$ ) in the LIFT printing technique [153]. Wu and Ringeisen fabricated capillary-scale branch/stem structures of human umbilical vein endothelial cells (HUVEC) similar to the vein structure on a leaf using biological laser printing (BioLP) [154]. Recently, a LAB bioprinter (laser-assisted bioprinting) was advanced for patterning of endothelial cells in situ [155]. The approach of this method was to develop organized vascular networks due to the cell self-assembly, which subsequently lead to increased bone tissue regeneration by enhancement of vascularization in engineered constructs. The comparison between randomly seeded endothelial cells and cells printed onto a collagen substrate containing human VEGF and MSCs, provided evidence for the applicability of LAB in clinical applications. The vascularized constructs method has been used to print smooth muscle cells and HUVECs sequentially adding into a branched structure 2D configuration [156].

In another study, bioinks based on thrombin and calcium have been deposited on a surface of fibrinogen to simulate the intrinsic solidifying process during wound healing [157]. This study established a dry inkjet printing method with in situ biomimetic gel formation where the printed fibrinogen exhibits explosive pressure that can model cell microvessels in two dimensions (2D) and form stable channels within 21 days [157].

Microtissues in the form of tissue spheroids and other small cell aggregates in 3D are ideal candidates to simulate tissue microenvironments in vivo, which can be reconstituted to generate reproducible complex tissues such as bone [158] and pancreas [159] and cancer tissue models for therapeutic purposes [160]. The assembly of this kind of spheroids can occur in a controlled manner by 3D bioprinting and microfluidic devices [160-162]. Therefore, these tissue spheroids must have a standard size and shape suitable for the continuous dispensing in the microtissues bioprinting process. Chen et al. biofabricated in vitro human 3D vascular cancer model where perfusion and microcirculation of tumor cells are tracked and monitored over time through confocal microscopy [161]. Lim et al. have recently reviewed microvascularized aggregates as a various $3 \mathrm{D}$ cancer models for drug screening [163].

The scalable biofabrication of a large volume of standard size is another essential issue that should be considered [164]. Large spheroids with a diameter $(>300 \mu \mathrm{m})$, or smaller co-culture spheroids are non-compatible for bioprinting. Hanging drop culture is an example of high maintenance culture methods that leads to small co-culture 
spheroid formation [165]. The suitability of vascularized spheroids formation has been investigated by several culture methods [166, 167]. Despite the development of multiple high-throughput spheroid culture systems, so far they have been used to produce monoculture spheroids [127] or nonvascularized co-cultures [148].

A method to produce prevascularized micro-sized aggregates and microspheres with tunable and controlled size which enables the formation a macrotissue in vivo in high yield still has not been reported. Furthermore, these prevascularized microspheres will be essential elements for 3D bioprinting of microtissue which is mimicking the particular human tissue histoarchitecture. To date, most of the engineered vascularized tissues are in range of $1 \mathrm{~mm}$ in size. However, microvascularization is required in large with high cell density $(\sim \mathrm{cm})$ to provide proper perfusion [119]. Moreover, the non-adherent microwell culture system can generate prevascularized microtissues with bioprinting-compatible geometry in a high-throughput manner [168]. Co-culture of human umbilical vein endothelial cells (HUVEC) with other supporting cell types such as adipose tissue-derived mesenchymal stem cells (ADSC) and human foreskin fibroblasts (HFF) in different ratios (HUVEC/ ADSC, HUVEC/HFF, HUVEC/ADSC/HFF) are used to study the impact of applied supporting cell types and cell ratio on spheroid and microvessel formation. The ability of the spheroids in random self-assembly into a larger macrotissue has been studied. Spheroids loaded with endothelial cells exhibited enhanced generation of a denser tissue microenvironment, inherent ECM secretion, and prevascularized network [169]. Overall, larger and complex vascularized tissue structures are made using prevascularized cell aggregates as cardinal building units which lead to precise control of representations of native tissues [166, 170]. Furthermore, these tissue complexes can be more appropriate than conventional animal models used for drug assessment, disease monitoring, and high-throughput screening [171].

Tissue spheroids are 3D living materials with certain measurable, and controllable composition, material, and biological properties. Enabling precise bioprinting of various shapes of spheroids onto functional gel substrates (i.e., alginate) has been demonstrated. Aiming to obtain fibrin constructs, the microvalve bioprinting has been used to print fibrinogen and thrombin in the form of microspheres, in which spheroids are embedded into the fibrin as a functional hydrogel. MSC/HUVEC spheroids with average diameter of
$300 \mu \mathrm{m}$ are then bioprinted into desired positions within the fibrin hydrogel before the constructs are fully cross-linked [154].

In another study, the matrix of spheroids is made of HUVEC, $3 \mathrm{t} 3$, and $4 \mathrm{t} 1$ cells in the diameter range of 80 to $200 \mu \mathrm{m}$. Eight MSc spheroids in different sizes were bioprinted, on top of each other without any gel support, to fabricate a hollow bridge shape for confirming the precise positioning control of aspiration-assisted bioprinting (AAB) [172]. Moreover, spheroids could be bioprinted into sacrificial hydrogels or functional hydrogels sequentially as scaffold-free bioprinting or scaffold-based bioprinting. Using this strategy, the bioprinting of non-uniform sized spheroids is enabled.

Self-assembled vascular microtissue spheroids allow large and complex vascular tissue engineering. For example, et al. showed microvascular tissue formation from entrapped cells within an RGD-modified alginate-based microgel. Microgel modification tuned the mechanosensing and ECM regulation resulting in microtissue self-assembly [161]. To develop the hollow vascular spheroids, Gentile et al. studied VEGFmediated fusion in the generation of embryonic mouse allantois-derived spheroids; analysis of VEGF-treated spheroids showed that treated spheroids are uniluminal [173]. This method produced the transformation of the inner network of small diameter endothelial tubes into a contiguous layer of cells that circumscribed a central lumen-like cavity. These uniluminal spheroids can promote formation of blood vessels and microvasculature while still retaining their hollow core [174].

The coating of spheroids with ECs is another strategy to fabricate vascularized macrotissues. Microtissues are coated with primary endothelial cells that can assemble to form macrotissues with endogenous vasculature [175]. The presence of induced pluripotent stem cell-derived endothelial cells on the surface of microbeads promoted the microvascular network sprouting and angiogenesis in a hepatic cell-dense 3D tissue [176]. It has been reported that in vivo implantation of vascular spheroids based on human endothelial cells leads to the significant production of blood microvessels and lymph [177]. Angiogenicity of dental pulp stem cells and endothelial cells self-assembly into capillaries led to increased blood perfusion in the implanted collagenbased scaffold [178]. Scientists showed that the anastomosis prevascularized endothelial-fibroblast aggregates generated microcapillaries resulting in high post-implanted cell 
viability [179], though further studies are required in large animal models to confirm potential of the above-discussed microtissues for the clinical applications.

Despite the advances, the architectural complexity of vascularized micro- and macrotissues is still challenging. The approach of scaffold-free vascular tissue engineering provides the possibility of designing vessels with various shapes and diameters. This method is fast, accurate, reliable and easily scalable [180]. Regarding this issue, bioprinting technology has been used to develop scaffold-free cell-laden construct. Jakab et al. studied 3D biofabrication of the ring and tube-like structures by 3D deposition of Chinese Hamster Ovary (CHO) cells-laden microspheres, leading to tunable cell-cell interactions and adhesion by varying hydrogels properties [181]. In addition, the embryonic cardiac cell aggregates and ECs-loaded structures have been bioprinted for cardiac tissue engineering, in which the ECs migrate to the space between aggregates allowing cell-cell interaction [182]. Due to cell-cell interaction provided proper ECM formation, injectable pre-cultured HUVEC and normal human lung fibroblasts (NHLF) cell-loaded fibrin microbeads present an excellent in vivo microvascularization in ischemic site after 7 days [183]. Tan et al. proposed and developed ring-shaped molds with alginate microdroplets. Spheroids comprising human aortic smooth muscle cells (hSMCs) and human umbilical vein endothelial cells (HUVECs) are deposited onto an alginate hydrogel substrate [164]. The spheroids fusion increased the levels of formation of toroidshaped tissue and lead to endogenous collagen secretion during in vitro culture. Alternatively, using an alginate-based bioink to bioprint cell aggregations within calcium chloride solution for crosslinking, enables the fabrication of zigzag cellular tubes structure [184].

Precise positioning of spheroids is a significant challenge. Spheroid density has a crucial role in the spheroid fusion [185]; therefore, the inhomogeneous fusion may ensue due to the inconsistent placement of spheroids [186]. In this regard, the spheroids are perfused into solid cylinders before printing. Cylindrical tissue unit fusion is faster and more continuous especially on large scale in comparison with spherical units [187]. These structures can be used for scale-up vascular tissue biofabrication [180].

Several types of vascular cells including smooth muscle cells and fibroblasts that have accumulated into various components lead to engineer multi-cellular microtissue
[188]. The multicellular spheroids or tubes with average diameter of 300 to $500 \mu \mathrm{m}$ have been bioprinted using agarose rods as non-adherent mold. The combination of different cells made it possible to obtain single-layer or double-layer blood vessels $[189,190]$. Maturation factors can activate endothelial cells, fibroblast and MScs which are micro-structured by layer-by-layer bioprinting on the hydrogel. This process leads to vascularization, which is confirmed by the gene expression in endothelial cells [191]; further details are available in a recent review by Sarker et al. [192].

\section{Conclusion and Future Outlook}

Studies on vascular tissue engineering are growing rapidly and can be further improved using advanced technologies such as 3D bioprinting and microfluidic devices. Traditionally, the growth factors and angiogenic progenitors are incorporated into the scaffold to increase cell infiltration and vascularization. However, the biological response is limited, particularly in large and cell dense tissues. It is therefore preferred that the microvascularized systems used in the engineered construct allow proper cell-cell and cell-ECM interactions. Prevascularized micro-sized aggregates or microspheres enhance the vascularization potential of the structures and save the time required for angiogenicity to advance within the scaffold. However, precision deposition of microvascularized spheres within the scaffold and clinical application of such prevascularized scaffolds are still challenging. Recently, comprehensive clinical trials that are underway or planned in the near future seem to show that we are entering a new era of vascular disease treatment.

Open Access This article is licensed under a Creative Commons Attribution 4.0 International License, which permits use, sharing, adaptation, distribution and reproduction in any medium or format, as long as you give appropriate credit to the original author(s) and the source, provide a link to the Creative Commons licence, and indicate if changes were made. The images or other third party material in this article are included in the article's Creative Commons licence, unless indicated otherwise in a credit line to the material. If material is not included in the article's Creative Commons licence and your intended use is not permitted by statutory regulation or exceeds the permitted use, you will need to obtain permission directly from the copyright holder. To view a copy of this licence, visit http://creativecommons.org/licenses/by/4.0/. 


\section{References}

1. B.K. Gale, A.R. Jafek, C.J. Lambert, B.L. Goenner, H. Moghimifam et al., A review of current methods in microfluidic device fabrication and future commercialization prospects. Inventions 3(3), 60 (2018). https://doi.org/10.3390/ inventions 3030060

2. K. Ren, J. Zhou, H.K. Wu, Materials for microfluidic chip fabrication. Acc. Chem. Res. 46(11), 2396-2406 (2013). https://doi.org/10.1021/ar300314s

3. R. Riahi, A. Tamayol, S.A.M. Shaegh, A.M. Ghaemmaghami, M.R. Dokmeci et al., Microfluidics for advanced drug delivery systems. Curr. Opin. Chem. Eng. 7, 101-112 (2015). https://doi.org/10.1016/j.coche.2014.12.001

4. A.K. Au, W. Huynh, L.F. Horowitz, A. Folch, 3d-printed microfluidics. Angew. Chem. Int. Ed. 55(12), 3862-3881 (2016). https://doi.org/10.1002/anie.201504382

5. A. Hasan, A. Paul, N.E. Vrana, X. Zhao, A. Memic et al., Microfluidic techniques for development of $3 \mathrm{~d}$ vascularized tissue. Biomaterials 35(26), 7308-7325 (2014). https://doi. org/10.1016/j.biomaterials.2014.04.091

6. R.W. Barrs, J. Jia, S.E. Silver, M. Yost, Y. Mei, Biomaterials for bioprinting microvasculature. Chem. Rev. 120(19), 10887-10949 (2020). https://doi.org/10.1021/acs.chemrev. 0c00027

7. Y.S. Zhang, A. Khademhosseini, Vascular tissue engineering: the role of 3d bioprinting. Tissue Eng. Vas. Grafts 321-338 (2020). doi: https://doi.org/10.1007/978-3-030-05336-9_11

8. L. Shao, Q. Gao, C. Xie, J. Fu, M. Xiang et al., Directly coaxial 3d bioprinting of large-scale vascularized tissue constructs. Biofabrication 12(3), 035014 (2020). https://doi.org/ 10.1088/1758-5090/ab7e76

9. Y. Wu, Y. Zhang, Y. Yu, I.T. Ozbolat, in 3D Coaxial Bioprinting of Vasculature. ed.by (Springer; 2020), pp. 171-181. https://doi.org/10.1007/978-1-0716-0520-2_11

10. S.F. Parsa, A. Vafajoo, A. Rostami, R. Salarian, M. Rabiee et al., Early diagnosis of disease using microbead array technology: a review. Anal. Chim. Acta 1032, 1-17 (2018). https://doi.org/10.1016/j.aca.2018.05.011

11. E.P. Chen, Z. Toksoy, B.A. Davis, J. Geibel, Biotechnology. $3 \mathrm{D}$ bioprinting of vascularized tissues for in vitro and in vivo applications. Front. Bioeng. Biotech. 9, 326 (2021). https:// doi.org/10.3389/fbioe.2021.664188

12. B. Zhang, Y. Luo, L. Ma, L. Gao, Y. Li et al., Manufacturing. 3D bioprinting: An emerging technology full of opportunities and challenges. Bio-des. Manuf. 1(1), 2-13 (2018). https:// doi.org/10.1007/s42242-018-0004-3

13. S. Hajebi, N. Rabiee, M. Bagherzadeh, S. Ahmadi, M. Rabiee et al., Stimulus-responsive polymeric nanogels as smart drug delivery systems. Acta Biomater. 92, 1-18 (2019). https://doi. org/10.1016/j.actbio.2019.05.018

14. K. Lee, E.A. Silva, D. Mooney, Growth factor delivery-based tissue engineering: general approaches and a review of recent developments. J. R. Soc. Interface 8(55), 153-170 (2011). https://doi.org/10.1098/rsif.2010.0223
15. L.M.C. Aguilar, S.M. Silva, S. Moulton, Growth factor delivery: Defining the next generation platforms for tissue engineering. J. Control. Release 306, 40-58 (2019). https://doi. org/10.1016/j.jconrel.2019.05.028

16. M.R. Casanova, C. Oliveira, E.M. Fernandes, R.L. Reis, T.H. Silva et al., Spatial immobilization of endogenous growth factors to control vascularization in bone tissue engineering. Biomater. Sci. 8(9), 2577-2589 (2020). https://doi.org/10. 1039/D0BM00087F

17. S. Toosi, J. Behravan, Osteogenesis and bone remodeling: A focus on growth factors and bioactive peptides. Adv. Drug Delivery Rev. 46(3), 326-340 (2020). https://doi.org/10. 1002/biof.1598

18. R. Burdis, D.J. Kelly, Biofabrication and bioprinting using cellular aggregates, microtissues and organoids for the engineering of musculoskeletal tissues. Acta Biomater. (Accepted, 2021). https://doi.org/10.2139/ssrn.3739622

19. G. Nilsson Hall, L.F. Mendes, C. Gklava, L. Geris, F.P. Luyten et al., Developmentally engineered callus organoid bioassemblies exhibit predictive in vivo long bone healing. Adv. Sci. 7(2), 1902295 (2020). https://doi.org/10.1002/advs. 201902295

20. J. Rouwkema, B.F. Koopman, C.A.V. Blitterswijk, W.J. Dhert, J. Malda, Supply of nutrients to cells in engineered tissues. Biotech. Genetic Eng. Rev. 26(1), 163-178 (2009). https://doi.org/10.5661/bger-26-163

21. L.M. Miller, A. Gal, Cardiovascular System and Lymphatic Vessels. Pathologic Basis of Veterinary Disease, 6th edn. (2017), pp. 561-616. https://doi.org/10.1016/B978-0-32335775-3.00010-2

22. A.P. Slovinski, L.A. Hajjar, C. Ince, Microcirculation in cardiovascular diseases. J. Cardiothor. Vas. Anesth. 33(12), 3458-3468 (2019). https://doi.org/10.1053/j.jvca.2019.08. 008

23. N. Rabiee, M.T. Yaraki, S.M. Garakani, S.M. Garakani, S. Ahmadi et al., Recent advances in porphyrin-based nanocomposites for effective targeted imaging and therapy. Biomaterials 232, 119707 (2020). https://doi.org/10.1016/j.biomateria 1s.2019.119707

24. Y. Wang, C. Xue, R. Surgery, Research progress of vascularization in tissue engineering. J. Tissue Engin. Reconstr. Surg. 9(4), 232-234 (2013)

25. D. Gholobova, L. Terrie, M. Gerard, H. Declercq, L. Thorrez, Vascularization of tissue-engineered skeletal muscle constructs. Biomaterials 235, 119708 (2020). https://doi.org/10. 1016/j.biomaterials.2019.119708

26. S. Ahmadi, N. Rabiee, M. Bagherzadeh, F. Elmi, Y. Fatahi et al., Stimulus-responsive sequential release systems for drug and gene delivery. Nano Today 34, 100914 (2020). https:// doi.org/10.1016/j.nantod.2020.100914

27. P. Baldwin, D.J. Li, D.A. Auston, H.S. Mir, R.S. Yoon et al., Autograft, allograft, and bone graft substitutes: clinical evidence and indications for use in the setting of orthopaedic trauma surgery. J. Orthopaedic Trauma 33(4), 203-213 (2019). https://doi.org/10.1097/BOT.0000000000001420 
28. J.R. Yu, J. Navarro, J.C. Coburn, B. Mahadik, J. Molnar et al., Current and future perspectives on skin tissue engineering: Key features of biomedical research, translational assessment, and clinical application. Adv. Health. Mater. 8(5), 1801471 (2019). https://doi.org/10.1002/adhm.201801471

29. S. Nour, N. Baheiraei, R. Imani, N. Rabiee, M. Khodaei et al., Bioactive materials: A comprehensive review on interactions with biological microenvironment based on the immune response. J. Bionic Engin. 16(4), 563-581 (2019). https:// doi.org/10.1007/s42235-019-0046-Z

30. W.D. Tucker, Y. Arora, K. Mahajan, Anatomy, Blood Vessels. (2017).

31. D.B. McMillan, R.J. Harris, An Atlas of Comparative Vertebrate Histology. (Academic Press; 2018).

32. W.D. Tucker, B.J.S. Burns, Anatomy, thorax, heart pulmonary arteries. StatPearls [Internet] (2018).

33. S. Maghsoudi, B.T. Shahraki, N. Rabiee, Y. Fatahi, R. Dinarvand et al., Burgeoning polymer nano blends for improved controlled drug release: a review. Inter. J. Nanomed. 15, 4363 (2020). https://doi.org/10.2147/IJN.S252237

34. S. Nour, N. Baheiraei, R. Imani, M. Khodaei, A. Alizadeh et al., A review of accelerated wound healing approaches: Biomaterial-assisted tissue remodeling. J. Mater. Sci. Mater. Med. 30(10), 1-15 (2019). https://doi.org/10.1007/ s10856-019-6319-6

35. D. Gomez, K. Kessler, L.F. Borges, B. Richard, Z. Touat et al., Smad2-dependent protease nexin-1 overexpression differentiates chronic aneurysms from acute dissections of human ascending aorta. Arterioscler. Thromb. Vasc. Biol. 33(9), 2222-2232 (2013). https://doi.org/10.1161/ATVBA HA. 113.301327

36. W.D. Tucker, B.J.S. Burns, Anatomy, Thorax, Heart Pulmonary Arteries (2018).

37. S.M. Nasr, N. Rabiee, S. Hajebi, S. Ahmadi, Y. Fatahi et al., Biodegradable nanopolymers in cardiac tissue engineering: From concept towards nanomedicine. Inter. J. Nanomed. 15, 4205 (2020). https://doi.org/10.2147/IJN.S245936

38. A. Vafajoo, A. Rostami, S.F. Parsa, R. Salarian, N. Rabiee et al., Multiplexed microarrays based on optically encoded microbeads. Biomed. Microdev. 20(3), 1-14 (2018). https:// doi.org/10.1007/s10544-018-0314-4

39. J.L. Cronenwett, K.W. Johnston, Rutherford's Vascular Surgery e-Book. (Elsevier Health Sciences; 2014).

40. M. Tavakolizadeh, A. Pourjavadi, M. Ansari, H. Tebyanian, S. Tabaei et al., An environmentally friendly wound dressing based on a self-healing, extensible and compressible antibacterial hydrogel. Green Chem. 23(3), 1312-1329 (2021). https://doi.org/10.1039/D0GC02719G

41. A. Chanakira, R. Dutta, R. Charboneau, R. Barke, S.M. Santilli et al., Hypoxia differentially regulates arterial and venous smooth muscle cell proliferation via PDGFR- $\beta$ and VEGFR-2 expression. Am. J. Physiol. Heart Circ. Physiol. 302(5), H1173-H1184 (2012). https://doi.org/10.1152/ajphe art.00411.2011
42. J. Paek, S.E. Park, Q. Lu, K.-T. Park, M. Cho, J.M. Oh et al., Microphysiological engineering of self-assembled and perfusable microvascular beds for the production of vascularized three-dimensional human microtissues. ACS Nano 13(7), 7627-7643 (2019). https://doi.org/10.1021/acsnano.9b00686

43. L. Sherwood, Human Physiology: From Cells to Systems (Cengage learning; 2015).

44. S. Maghsoudi, B.T. Shahraki, N. Rabiee, R. Afshari, Y. Fatahi et al., Recent advancements in aptamer-bioconjugates: Sharpening stones for breast and prostate cancers targeting. J. Drug Deliv. Sci. Technol. 53, 101146 (2019). https://doi.org/10. 1016/j.jddst.2019.101146

45. N. Rabiee, M. Bagherzadeh, M. Heidarian Haris, A.M. Ghadiri, F. Matloubi Moghaddam et al., Polymer-coated $\mathrm{NH}_{2}$-UIO-66 for the codelivery of DOX/pCRISPR. ACS Appl. Mater. Interf. 13(9), 10796-10811 (2021). https://doi. org/10.1021/acsami.1c01460

46. E.C. Novosel, C. Kleinhans, P. Kluger, Vascularization is the key challenge in tissue engineering. Adv. Drug Deliv. Rev. 63(4-5), 300-311 (2011). https://doi.org/10.1016/j.addr. 2011.03.004

47. M.W. Laschke, T. Später, M. Menger, Microvascular fragments: more than just natural vascularization units. Trends Biotechn. 39, 24-33 (2020). https://doi.org/10.1016/j.tibtech. 2020.06.001

48. O. Akhavan, E. Ghaderi, E. Abouei, S. Hatamie, E. Ghasemi, Accelerated differentiation of neural stem cells into neurons on ginseng-reduced graphene oxide sheets. Carbon 66, 395406 (2014). https://doi.org/10.1016/j.carbon.2013.09.015

49. Y. Wang, W.C. Lee, K.K. Manga, P.K. Ang, J. Lu et al., Fluorinated graphene for promoting neuro-induction of stem cells. Adv. Mater. 24(31), 4285-4290 (2012). https://doi.org/ 10.1002/adma.201200846

50. O. Akhavan, Graphene scaffolds in progressive nanotechnology/stem cell-based tissue engineering of the nervous system. J. Mater. Chem. B 4(19), 3169-3190 (2016). https://doi.org/ 10.1039/C6TB00152A

51. M.H. Norahan, M. Amroon, R. Ghahremanzadeh, N. Rabiee, N. Baheiraei, Reduced graphene oxide: osteogenic potential for bone tissue engineering. IET Nanobiotechn. 13(7), 720725 (2019). https://doi.org/10.1049/iet-nbt.2019.0125

52. O. Akhavan, E. Ghaderi, M. Shahsavar, Graphene nanogrids for selective and fast osteogenic differentiation of human mesenchymal stem cells. Carbon 59, 200-211 (2013). https:// doi.org/10.1016/j.carbon.2013.03.010

53. C. Heo, J. Yoo, S. Lee, A. Jo, S. Jung et al., The control of neural cell-to-cell interactions through non-contact electrical field stimulation using graphene electrodes. Biomaterials 32(1), 19-27 (2011). https://doi.org/10.1016/j.biomaterials. 2010.08.095

54. H. Amani, E. Mostafavi, H. Arzaghi, S. Davaran, A. Akbarzadeh et al., Three-dimensional graphene foams: Synthesis, properties, biocompatibility, biodegradability, and applications in tissue engineering. ACS Biomater. Sci. Engin. 5(1), 193-214 (2018). https://doi.org/10.1021/acsbiomaterials. $8 \mathrm{~b} 00658$ 
55. S. Bahrami, N. Baheiraei, M. Mohseni, M. Razavi, A. Ghaderi et al., Three-dimensional graphene foam as a conductive scaffold for cardiac tissue engineering. J. Biomater. Appl. 34(1), 74-85 (2019). https://doi.org/10.1177/08853 28219839037

56. O. Akhavan, E. Ghaderi, S.A. Shirazian, R. Rahighi, Rolled graphene oxide foams as three-dimensional scaffolds for growth of neural fibers using electrical stimulation of stem cells. Carbon 97, 71-77 (2016). https://doi.org/10.1016/j. carbon.2015.06.079

57. K. Ashtari, H. Nazari, H. Ko, P. Tebon, M. Akhshik et al., Electrically conductive nanomaterials for cardiac tissue engineering. Adv. Drug Delivery Rev. 144, 162-179 (2019). https://doi.org/10.1016/j.addr.2019.06.001

58. R.O. Hynes, The extracellular matrix: Not just pretty fibrils. Science 326(5957), 1216-1219 (2009). https://doi.org/10. 1126/science. 1176009

59. N. Rabiee, M. Bagherzadeh, A.M. Ghadiri, Y. Fatahi, N. Baheiraei et al., Bio-multifunctional noncovalent porphyrin functionalized carbon-based nanocomposite. Sci. Rep. 11(1), 1-15 (2021). https://doi.org/10.1038/s41598-021-86119-Z

60. N. Rabiee, S. Ahmadvand, S. Ahmadi, Y. Fatahi, R. Dinarvand et al., Carbosilane dendrimers: drug and gene delivery applications. J. Drug Deliv. Sci. Techn. 101879 (2020).https://doi.org/10.1016/j.jddst.2020.101879

61. M.M. Martino, P.S. Briquez, A. Ranga, M.P. Lutolf, J.A. Hubbell, Heparin-binding domain of fibrin (ogen) binds growth factors and promotes tissue repair when incorporated within a synthetic matrix. Proc. Natl. Acad. Sci. 110(12), 4563-4568 (2013). https://doi.org/10.1073/pnas.1221602110

62. M.M. Martino, S. Brkic, E. Bovo, M. Burger, D.J. Schaefer et al., Extracellular matrix and growth factor engineering for controlled angiogenesis in regenerative medicine. Front. Bioeng. Biotechnol. 3, 45 (2015). https://doi.org/10.3389/fbioe. 2015.00045

63. E. Ruvinov, J. Leor, S. Cohen, The effects of controlled hgf delivery from an affinity-binding alginate biomaterial on angiogenesis and blood perfusion in a hindlimb ischemia model. Biomaterials 31(16), 4573-4582 (2010). https://doi. org/10.1016/j.biomaterials.2010.02.026

64. J.E. Saik, D.J. Gould, E.M. Watkins, M.E. Dickinson, J.L. West, Covalently immobilized platelet-derived growth factorbb promotes angiogenesis in biomimetic poly (ethylene glycol) hydrogels. Acta Biomater. 7(1), 133-143 (2011). https:// doi.org/10.1016/j.actbio.2010.08.018

65. Q. Liu, Y. Huang, Y. Lan, Q. Zuo, C. Li et al., Acceleration of skin regeneration in full-thickness burns by incorporation of BFGF-loaded alginate microspheres into a CMCS-PVA hydrogel. J. Tissue Engin. Regen. Med. 11(5), 1562-1573 (2017). https://doi.org/10.1002/term.2057

66. S. Fleischer, A. Shapira, R. Feiner, T. Dvir, Modular assembly of thick multifunctional cardiac patches. Proc. Natl. Acad. Sci. 114(8), 1898-1903 (2017). https://doi.org/10.1073/pnas. 1615728114

67. M. Omidi, V. Mansouri, L. Mohammadi Amirabad, L. Tayebi, Impact of lipid/magnesium hydroxide hybrid nanoparticles on the stability of vascular endothelial growth factor-loaded PLGA microspheres. ACS Appl. Mater. Interf. (2021). https://doi.org/10.1021/acsami.0c22140

68. Z.D. Zhang, Y.Q. Xu, F. Chen, J.F. Luo, C. Liu, vessels. Sustained delivery of vascular endothelial growth factor using a dextran/poly (lactic-co-glycolic acid)-combined microsphere system for therapeutic neovascularization. Heart Vessels 34(1), 167-176 (2019). https://doi.org/10.1007/ s00380-018-1230-5

69. M. Omidi, L. Almeida, L. Tayebi, A. Biochemistry, Microfluidic-assisted fabrication of reverse micelle/PLGA hybrid microspheres for sustained vascular endothelial growth factor delivery. Biotechn. Appl. Biochem. 68, 616-625 (2020). https://doi.org/10.1002/bab.1971

70. M. Omidi, M. Hashemi, L. Tayebi, Microfluidic synthesis of PLGA/carbon quantum dot microspheres for vascular endothelial growth factor delivery. RSC Adv. 9(57), 3324633256 (2019). https://doi.org/10.1039/C9RA06279C

71. G. Della Porta, M.C. Ciardulli, N. Maffulli, A review. Microcapsule technology for controlled growth factor release in musculoskeletal tissue engineering. Sports Med. Arthros. Rev. 26(2), e2-e9 (2018). https://doi.org/10.1097/JSA.00000 00000000188

72. S. Fleischer, D.N. Tavakol, G. Vunjak-Novakovic, From arteries to capillaries: Approaches to engineering human vasculature. Adv. Funct. Mater. 30(37), 1910811 (2020). https://doi. org/10.1002/adfm.201910811

73. A. Moncion, K.J. Arlotta, E.G. O’Neill, M. Lin, L.A. Mohr et al., In vitro and in vivo assessment of controlled release and degradation of acoustically responsive scaffolds. Acta Biomater. 46, 221-233 (2016). https://doi.org/10.1016/j.actbio.2016.09.026

74. R.E. Liebano, A. Machado, Vascular endothelial growth factor release following electrical stimulation in human subjects. Adv. Wound Care 3(2), 98-103 (2014). https://doi.org/10. 1089/wound.2013.0427

75. O. Akhavan, E. Ghaderi, The use of graphene in the selforganized differentiation of human neural stem cells into neurons under pulsed laser stimulation. J. Mater. Chem. B 2(34), 5602-5611 (2014). https://doi.org/10.1039/C4TB00668B

76. O. Akhavan, E. Ghaderi, Flash photo stimulation of human neural stem cells on graphene/ $\mathrm{TiO}_{2}$ heterojunction for differentiation into neurons. Nanoscale 5(21), 10316-10326 (2013). https://doi.org/10.1039/c3nr02161k

77. C. Dionigi, L. Lungaro, V. Goranov, A. Riminucci, Y. PineiroRedondo et al., Smart magnetic poly (n-isopropylacrylamide) to control the release of bio-active molecules. J. Mater. Sci.: Mater. Med. 25(10), 2365-2371 (2014). https://doi.org/10. 1007/s10856-014-5159-7

78. N. Kuzmic, T. Moore, D. Devadas, E.W. Young, Modelling of endothelial cell migration and angiogenesis in microfluidic cell culture systems. Biomech. Model. Mechanobiol. 18(3), 717-731 (2019). https://doi.org/10.1007/ s10237-018-01111-3

79. S. Kim, H. Lee, M. Chung, N.L. Jeon, Engineering of functional, perfusable $3 \mathrm{~d}$ microvascular networks on a chip. Lab 
Chip 13(8), 1489-1500 (2013). https://doi.org/10.1039/c3lc4 $1320 \mathrm{a}$

80. A.T. Alsop, J.C. Pence, D.W. Weisgerber, B.A. Harley, R.C. Bailey, Photopatterning of vascular endothelial growth factor within collagen-glycosaminoglycan scaffolds can induce a spatially confined response in human umbilical vein endothelial cells. Acta Biomater. 10(11), 4715-4722 (2014). https:// doi.org/10.1016/j.actbio.2014.07.002

81. M.H. Rich, M.K. Lee, K. Baek, J.H. Jeong, D.H. Kim et al., Material-mediated proangiogenic factor release pattern modulates quality of regenerated blood vessels. J. Control. Release 196, 363-369 (2014). https://doi.org/10.1016/j.jconr el.2014.10.020

82. V.S. Shirure, A. Lezia, A. Tao, L.F. Alonzo, S.C. George, Low levels of physiological interstitial flow eliminate morphogen gradients and guide angiogenesis. Angiogenesis 20(4), 493-504 (2017). https://doi.org/10.1007/s 10456-017-9559-4

83. H.A. Strobel, A.D. Dikina, K. Levi, L.D. Solorio, E. Alsberg et al., Cellular self-assembly with microsphere incorporation for growth factor delivery within engineered vascular tissue rings. Tissue Engin. Part A 23(3-4), 143-155 (2017). https:// doi.org/10.1089/ten.tea.2016.0260

84. A.F. Godier-Furnémont, T.P. Martens, M.S. Koeckert, L. Wan, J. Parks et al., Composite scaffold provides a cell delivery platform for cardiovascular repair. Proc. Natl. Acad. Sci. 108(19), 7974-7979 (2011). https://doi.org/10.1073/pnas. 1104619108

85. H.-M. Cho, K.-H. Lee, Y.-M. Shen, T.-J. Shin, P.-D. Ryu et al., Transplantation of hMSCs genome edited with LEF1 improves cardio-protective effects in myocardial infarction. Mol. Therapy-Nucleic Acids 19, 1186-1197 (2020). https:// doi.org/10.1016/j.omtn.2020.01.007

86. E.A. Phelps, D.M. Headen, W.R. Taylor, P.M. Thulé, A.J. García, Vasculogenic bio-synthetic hydrogel for enhancement of pancreatic islet engraftment and function in type 1 diabetes. Biomaterials 34(19), 4602-4611 (2013). https://doi.org/ 10.1016/j.biomaterials.2013.03.012

87. P. Au, J. Tam, D. Fukumura, R.K. Jain, in Small Blood Vessel Engineering. (Springer; 2008), pp. 183-195. https://doi.org/ 10.1007/978-1-59745-443-8_11

88. Y.-W. Cheng, D.J. Shiwarski, R.L. Ball, K.A. Whitehead, A.W. Feinberg, Engineering aligned skeletal muscle tissue using decellularized plant-derived scaffolds. ACS Biomater. Sci. Eng. 6(5), 3046-3054 (2020). https://doi.org/10.1021/ acsbiomaterials.0c00058

89. A. Dingle, K. Yap, Y. Gerrand, C. Taylor, E. Keramidaris et al., Characterization of isolated liver sinusoidal endothelial cells for liver bioengineering. Angiogenesis 21(3), 581-597 (2018). https://doi.org/10.1007/s10456-018-9610-0

90. J.A. Whisler, M.B. Chen, R.D. Kamm, Control of perfusable microvascular network morphology using a multiculture microfluidic system. Tissue Eng. Part C: Methods 20(7), 543-552 (2014). https://doi.org/10.1089/ten.tec.2013.0370

91. C.M. Ghajar, X. Chen, J.W. Harris, V. Suresh, C.C. Hughes et al., The effect of matrix density on the regulation of 3-d capillary morphogenesis. Biophys. J. 94(5), 1930-1941 (2008). https://doi.org/10.1529/biophysj.107.120774

92. S. Jeon, J.H. Heo, M.K. Kim, W. Jeong, H. Kang, High-precision $3 \mathrm{~d}$ bio-dot printing to improve paracrine interaction between multiple types of cell spheroids. Adv. Funct. Mater. 30(52), 2005324 (2020). https://doi.org/10.1002/adfm.20200 5324

93. S. Bersini, M. Gilardi, G.S. Ugolini, V. Sansoni, G. Talo et al., Engineering an environment for the study of fibrosis: a $3 \mathrm{~d}$ human muscle model with endothelium specificity and endomysium. Cell Rep. 25(13), 3858-3868. e3854 (2018). https://doi.org/10.1016/j.celrep.2018.11.092

94. T. Kageyama, Y.-S. Chun, J.J.S.r. Fukuda, Hair follicle germs containing vascular endothelial cells for hair regenerative medicine. Sci. Rep. 11(1), 1-10 (2021). https://doi.org/10. 1038/s41598-020-79722-z

95. J. Kalucka, L.P. de Rooij, J. Goveia, K. Rohlenova, S.J. Dumas et al., Single-cell transcriptome atlas of murine endothelial cells. Cell 180(4), 764-779 (2020). https://doi. org/10.1016/j.cell.2020.01.015

96. A. Sivarapatna, M. Ghaedi, Y. Xiao, E. Han, B. Aryal et al., Engineered microvasculature in pdms networks using endothelial cells derived from human induced pluripotent stem cells. Cell Transp. 26(8), 1365-1379 (2017). https:// doi.org/10.1177/0963689717720282

97. M.R. Kelly-Goss, R.S. Sweat, P.C. Stapor, S.M. Peirce, W.L. Murfee, Targeting pericytes for angiogenic therapies. Microcirculation 21(4), 345-357 (2014). https://doi.org/10.1111/ micc. 12107

98. X.-Y. Wang, Z.-H. Jin, B.-W. Gan, S. Xie et al., Engineering interconnected $3 \mathrm{~d}$ vascular networks in hydrogels using molded sodium alginate lattice as the sacrificial template. Lab Chip 14(15), 2709-2716 (2014). https://doi.org/10.1039/ C4LC00069B

99. K.A. DiVito, M.A. Daniele, S.A. Roberts, F.S. Ligler, A.A. Adams, Microfabricated blood vessels undergo neoangiogenesis. Biomaterials 138, 142-152 (2017). https://doi.org/10. 1016/j.biomaterials.2017.05.012

100. S. Alimperti, T. Mirabella, V. Bajaj, W. Polacheck, D.M. Pirone et al., Three-dimensional biomimetic vascular model reveals a Rhoa, Rac1, and N-cadherin balance in mural cellendothelial cell-regulated barrier function. Proc. Natl. Acad. Sci. 114(33), 8758-8763 (2017). https://doi.org/10.1073/ pnas. 1618333114

101. T. Sun, Q. Shi, Y. Yao, J. Sun, H. Wang et al., Engineered tissue micro-rings fabricated from aggregated fibroblasts and microfibres for a bottom-up tissue engineering approach. Biofabrication 11(3), 035029 (2019). https://doi.org/10.1088/ 1758-5090/ab1ee5

102. C. Peticone, D.D.S. Thompson, N. Dimov, B. Jevans, N. Glass et al., Characterisation of osteogenic and vascular responses of hmscs to Ti-Co doped phosphate glass microspheres using a microfluidic perfusion platform. J. Tissue Eng. Regen. Med. 11, 2041731420954712 (2020). https:// doi.org/10.1177/2041731420954712 
103. A. Peterson, D. Caldwell, A. Rioja, R. Rao, A. Putnam et al., Vasculogenesis and angiogenesis in modular collagen-fibrin microtissues. Biomater. Sci. 2(10), 1497-1508 (2014). https://doi.org/10.1039/C4BM00141A

104. G. Yang, B. Mahadik, J.Y. Choi, R.Y. Justine, T. Mollot et al., Fabrication of centimeter-sized $3 \mathrm{~d}$ constructs with patterned endothelial cells through assembly of cell-laden microbeads as a potential bone graft. Acta Biomater. 121, 204-213 (2021). https://doi.org/10.1016/j.actbio.2020.11. 040

105. C. Patsch, L. Challet-Meylan, E.C. Thoma, E. Urich, T. Heckel et al., Generation of vascular endothelial and smooth muscle cells from human pluripotent stem cells. Nat. Cell Biol. 17(8), 994-1003 (2015). https://doi.org/10.1038/ncb32 05

106. G. Sriram, J.Y. Tan, I. Islam, A.J. Rufaihah, T. Cao, Efficient differentiation of human embryonic stem cells to arterial and venous endothelial cells under feeder-and serum-free conditions. Stem Cell Res. Therapy 6(1), 1-17 (2015). https://doi. org/10.1186/s13287-015-0260-5

107. S. Kusuma, Y.-I. Shen, D. Hanjaya-Putra, P. Mali, L. Cheng et al., Self-organized vascular networks from human pluripotent stem cells in a synthetic matrix. Proc. Natl. Acad. Sci. 110(31), 12601-12606 (2013). https://doi.org/10.1073/pnas. 1306562110

108. Y. Wu, R.-N. Zhang, J. Tang, Isolation and culture of vascular wall-resident cd34+ stem/progenitor cells. Cardiol. Plus 4(4), 116 (2019). https://doi.org/10.4103/cp.cp_19_19

109. S. Levenberg, J.S. Golub, M. Amit, J. Itskovitz-Eldor, R. Langer, Endothelial cells derived from human embryonic stem cells. Proc. Natl. Acad. Sci. 99(7), 4391-4396 (2002). https://doi.org/10.1073/pnas.032074999

110. H. Cho, B.L. Macklin, Y.-Y. Lin, L. Zhou, M.J. Lai et al., Ipsc-derived endothelial cell response to hypoxia via SDF1a/ CXCR4 axis facilitates incorporation to revascularize ischemic retina. JCI Insight 5(6), e131828 (2020). https:// doi.org/10.1172/jci.insight.131828

111. K.-B. Celie, Y. Toyoda, X. Dong, K.A. Morrison, P. Zhang et al., Microstructured hydrogel scaffolds containing differential density interfaces promote rapid cellular invasion and vascularization. Acta Biomater. 91, 144-158 (2019). https:// doi.org/10.1016/j.actbio.2019.04.027

112. J. Jamieson, B. Macklin, S. Gerecht, Pericytes derived from human pluripotent stem cells. Pericyte BiologyNovel Concepts 111-124 (2018). https://doi.org/10.1007/ 978-3-030-02601-1_9

113. A. Cochrane, H.J. Albers, R. Passier, C.L. Mummery, A. Van Den Berg et al., Advanced in vitro models of vascular biology: human induced pluripotent stem cells and organ-on-chip technology. Adv. Drug Deliv. Rev. 140, 68-77 (2019). https:// doi.org/10.1016/j.addr.2018.06.007

114. A. Dar, H. Domev, O. Ben-Yosef, M. Tzukerman, N. ZeeviLevin et al., Multipotent vasculogenic pericytes from human pluripotent stem cells promote recovery of murine ischemic limb. Circulation 125(1), 87-99 (2012). https:// doi.org/10.1161/CIRCULATIONAHA.111.048264
115. M. Wanjare, S. Kusuma, S. Gerecht, Defining differences among perivascular cells derived from human pluripotent stem cells. Stem Cell Rep. 2(5), 561-575 (2014). https:// doi.org/10.1016/j.stemcr.2014.03.004

116. E.A. Bulanova, E.V. Koudan, J. Degosserie, C. Heymans, F.D. Pereira et al., Bioprinting of a functional vascularized mouse thyroid gland construct. Biofabrication 9(3), 034105 (2017). https://doi.org/10.1088/1758-5090/aa7fdd

117. N. Mekhileri, K. Lim, G. Brown, I. Mutreja, B. Schon et al., Automated 3d bioassembly of micro-tissues for biofabrication of hybrid tissue engineered constructs. Biofabrication 10(2), 024103 (2018). https://doi.org/10.1088/1758-5090/ aa9ef1

118. L. Gutzweiler, S. Kartmann, K. Troendle, L. Benning, G. Finkenzeller et al., Large scale production and controlled deposition of single huvec spheroids for bioprinting applications. Biofabrication 9(2), 025027 (2017). https://doi.org/ 10.1088/1758-5090/aa7218

119. N.I. Moldovan, N. Hibino, K.J.T.E.P.B.R. Nakayama, Principles of the kenzan method for robotic cell spheroid-based three-dimensional bioprinting. Tissue Eng. Part B: Rev. 23(3), 237-244 (2017). https://doi.org/10.1089/ten.teb. 2016.0322

120. B.C. Ip, F. Cui, A. Tripathi, J.R.J.B. Morgan, The biogripper: A fluid-driven micro-manipulator of living tissue constructs for additive bio-manufacturing. Biofabrication 8(2), 025015 (2016). https://doi.org/10.1088/1758-5090/8/ $2 / 025015$

121. A.M. Blakely, K.L. Manning, A. Tripathi, J.R. Morgan, Biopick, place, and perfuse: a new instrument for three-dimensional tissue engineering. Tissue Eng. Part C: Methods 21(7), 737-746 (2015). https://doi.org/10.1089/ten.tec.2014.0439

122. Y. Yu, K.K. Moncal, J. Li, W. Peng, I. Rivero et al., Threedimensional bioprinting using self-assembling scalable scaffold-free "tissue strands" as a new bioink. Sci. Rep. 6(1), 1-11 (2016). https://doi.org/10.1038/srep28714

123. Q. Mao, Y. Wang, Y. Li, S. Juengpanich, W. Li et al., Fabrication of liver microtissue with liver decellularized extracellular matrix (dECM) bioink by digital light processing (DLP) bioprinting. Mater. Sci. Eng. C 109, 110625 (2020). https:// doi.org/10.1016/j.msec.2020.110625

124. V. Mironov, R.P. Visconti, V. Kasyanov, G. Forgacs, C.J. Drake et al., Organ printing: tissue spheroids as building blocks. Biomaterials 30(12), 2164-2174 (2009). https://doi. org/10.1016/j.biomaterials.2008.12.084

125. M.E. Prendergast, G. Montoya, T. Pereira, J. Lewicki, R. Solorzano et al., Microphysiological systems: automated fabrication via extrusion bioprinting. Microphysiol. Syst. 2, 1-16 (2018). https://doi.org/10.21037/mps.2018.03.01

126. W. Lee, Y. Hong, G. Dai, 3d bioprinting of vascular conduits for pediatric congenital heart repairs. Transl. Res. 211, 35-45 (2019). https://doi.org/10.1016/j.trsl.2019.03.007

127. H. Xu, J. Casillas, C. Xu, Effects of printing conditions on cell distribution within microspheres during inkjet-based bioprinting. AIP Adv. 9(9), 095055 (2019). https://doi.org/ $10.1063 / 1.5116371$ 
128. S. Zhang, G. Li, J. Man, S. Zhang, J. Li et al., Fabrication of microspheres from high-viscosity bioink using a novel microfluidic-based 3d bioprinting nozzle. Micromachines 11(7), 681 (2020). https://doi.org/10.3390/mi11070681

129. J. Kim, I.K. Shim, D.G. Hwang, Y.N. Lee, M. Kim et al., 3d cell printing of islet-laden pancreatic tissue-derived extracellular matrix bioink constructs for enhancing pancreatic functions. J. Mater. Chem. B 7(10), 1773-1781 (2019). https://doi.org/10.1039/C8TB02787K

130. Y. Ji, Q. Yang, G. Huang, M. Shen, Z. Jian et al., Improved resolution and fidelity of droplet-based bioprinting by upward ejection. ACS Biomater. Sci. Eng. 5(8), 4112-4121 (2019). https://doi.org/10.1021/acsbiomaterials.9b00400

131. S. Yamaguchi, A. Ueno, Y. Akiyama, K. Morishima, Cell patterning through inkjet printing of one cell per droplet. Biofabrication 4(4), 045005 (2012). https://doi.org/10. 1088/1758-5082/4/4/045005

132. L. Benning, L. Gutzweiler, K. Tröndle, J. Riba, R. Zengerle et al., Assessment of hydrogels for bioprinting of endothelial cells. J. Biomed. Mater. Res. Part A 106(4), 935-947 (2018). https://doi.org/10.1002/jbm.a.36291

133. W.C. Wilson Jr., T. Boland, Cell and organ printing 1: Protein and cell printers. Anat. Rec. 272(2), 491-496 (2003). https://doi.org/10.1002/ar.a.10057

134. D. Murata, K. Arai, K.J.A.h.m. Nakayama, Scaffold-free bio-3d printing using spheroids as "bio-inks" for tissue (re-) construction and drug response tests. Adv. Healthcare Mater. 9(15), 1901831 (2020). https://doi.org/10.1002/ adhm.201901831

135. I.N. Aguilar, L.J. Smith, D.J. Olivos III., T.-M.G. Chu, M.A. Kacena et al., Scaffold-free bioprinting of mesenchymal stem cells with the regenova printer: Optimization of printing parameters. Bioprinting 15, e00048 (2019). https:// doi.org/10.1016/j.bprint.2019.e00048

136. K. Nakayama, Kenzan Method for Scaffold-free Biofabrication (2021). https://doi.org/10.1007/978-3-030-58688-1

137. N.I. Moldovan, N. Hibino, K. Nakayama, Principles of the kenzan method for robotic cell spheroid-based threedimensional bioprinting. Tissue Eng. Part B: Rev. 23(3), 237-244 (2017). https://doi.org/10.1089/ten.teb.2016.0322

138. H. Matsushita, V. Nguyen, K. Nurminsky, N. Hibino, in Cardiac Tissue Creation with the Kenzan Method. (Springer; 2021), pp. 109-115. https://doi.org/10.1007/ 978-3-030-58688-1_8

139. M. Itoh, Y. Mukae, T. Kitsuka, K. Arai, A. Nakamura et al., Development of an immunodeficient pig model allowing long-term accommodation of artificial human vascular tubes. Nat. Commun. 10(1), 1-8 (2019). https://doi.org/ 10.1038/s41467-019-10107-1

140. X.-Y. Zhang, Y. Yanagi, Z. Sheng, K. Nagata, K. Nakayama et al., Regeneration of diaphragm with bio-3d cellular patch. Biomaterials 167, 1-14 (2018). https://doi.org/10. 1016/j.biomaterials.2018.03.012

141. A.M. Blakely, K.L. Manning, A. Tripathi, J. Morgan, Biopick, place, and perfuse: a new instrument for three-dimensional tissue engineering. Tissue Engin. Part C Methods
21(7), 737-746 (2015). https://doi.org/10.1089/ten.tec.2014. 0439

142. I.T., Ozbolat, Medicine. Scaffold-based or scaffold-free bioprinting: Competing or complementing approaches? J. Nanotechnol. Eng. Med. 6(2), 024701 (2015). https://doi.org/10. 1115/1.4030414

143. I.T. Ozbolat, Medicine. Scaffold-based or scaffold-free bioprinting: Competing or complementing approaches? J. Nanotechnol. Eng. Med. 6(2), 024701 (2015). https://doi.org/10. 1115/1.4030414

144. S. Zhang, Z. Wan, R.D. Kamm, Vascularized organoids on a chip: Strategies for engineering organoids with functional vasculature. Lab Chip 21(3), 473-488 (2021). https://doi.org/ 10.1039/D0LC01186J

145. C.-T. Kuo, C.-L. Chiang, R.Y.-J. Huang, H. Lee, A.M. Wo, Configurable $2 \mathrm{~d}$ and $3 \mathrm{~d}$ spheroid tissue cultures on bioengineered surfaces with acquisition of epithelial-mesenchymal transition characteristics. NPG Asia Mater. 4(9), e27 (2012). https://doi.org/10.1038/am.2012.50

146. K.C. Scheiner, F. Coulter, R.F. Maas-Bakker, G. Ghersi, T.T. Nguyen et al., Vascular endothelial growth factorreleasing microspheres based on poly ( $\varepsilon$-caprolactone-PEG$\varepsilon$-caprolactone)-b-poly (l-lactide) multiblock copolymers incorporated in a three-dimensional printed poly (dimethylsiloxane) cell macroencapsulation device. J. Pharm. Sci. 109(1), 863-870 (2020). https://doi.org/10.1016/j.xphs.2019. 10.028

147. X. Xu, C. Liang, X. Gao, H. Huang, X. Xing et al., Adipose tissue-derived microvascular fragments as vascularization units for dental pulp regeneration. J. Endodontics 47, 10921100 (2021). https://doi.org/10.1016/j.joen.2021.04.012

148. B.A. Juliar, M.T. Keating, Y.P. Kong, E.L. Botvinick, A. Putnam, Sprouting angiogenesis induces significant mechanical heterogeneities and ecm stiffening across length scales in fibrin hydrogels. Biomaterials 162, 99-108 (2018). https:// doi.org/10.1016/j.biomaterials.2018.02.012

149. M. Mahmoudi, O. Akhavan, M. Ghavami, F. Rezaee, S. Ghiasi, Graphene oxide strongly inhibits amyloid beta fibrillation. Nanoscale 4(23), 7322-7325 (2012). https://doi.org/ $10.1039 / \mathrm{c} 2 \mathrm{nr} 31657 \mathrm{a}$

150. L. De Moor, I. Merovci, S. Baetens, J. Verstraeten, P. Kowalska et al., High-throughput fabrication of vascularized spheroids for bioprinting. Biofabrication 10(3), 035009 (2018). https://doi.org/10.1088/1758-5090/aac7e6

151. M. Kuss, B. Duan, in 3D Bioprinting for Cardiovascular Tissue Engineering. (Springer; 2017), pp. 167-182. https://doi. org/10.1007/978-3-319-53523-4_18

152. K. Haase, R. Kamm, Advances in on-chip vascularization. Regen. Med. 12(3), 285-302 (2017). https://doi.org/10.2217/ rme-2016-0152

153. P. Wu, B. Ringeisen, J. Callahan, M. Brooks, D. Bubb et al., The deposition, structure, pattern deposition, and activity of biomaterial thin-films by matrix-assisted pulsed-laser evaporation (MAPLE) and maple direct write. Thin Solid Films 398, 607-614 (2001). https://doi.org/10.1016/S00406090(01)01347-5 
154. O. Kérourédan, D. Hakobyan, M. Rémy, S. Ziane, N. Dusserre et al., In situ prevascularization designed by laserassisted bioprinting: Effect on bone regeneration. Biofabrication 11(4), 045002 (2019). https://doi.org/10.1088/17585090/ab2620

155. P. Wu, B. Ringeisen, Development of human umbilical vein endothelial cell (HUVEC) and human umbilical vein smooth muscle cell (HUVSMC) branch/stem structures on hydrogel layers via biological laser printing (BioLP). Biofabrication 2(1), 014111 (2010). https://doi.org/10.1088/ $1758-5082 / 2 / 1 / 014111$

156. X. Cui, T. Boland, Human microvasculature fabrication using thermal inkjet printing technology. Biomaterials 30(31), 6221-6227 (2009). https://doi.org/10.1016/j.bioma terials.2009.07.056

157. E. Fennema, N. Rivron, J. Rouwkema, C. van Blitterswijk, J. De Boer, Spheroid culture as a tool for creating 3d complex tissues. Trends Biotechnol. 31(2), 108-115 (2013). https://doi.org/10.1016/j.tibtech.2012.12.003

158. M. Hospodiuk, M. Dey, B. Ayan, D. Sosnoski, K.K. Moncal et al., Sprouting angiogenesis in engineered pseudo islets. Biofabrication 10(3), 035003 (2018). https://doi.org/10. 1088/1758-5090/aab002

159. W. Peng, P. Datta, B. Ayan, V. Ozbolat, D. Sosnoski et al., $3 \mathrm{~d}$ bioprinting for drug discovery and development in pharmaceutics. Acta Biomater. 57, 26-46 (2017). https://doi. org/10.1016/j.actbio.2017.05.025

160. C. Norotte, F.S. Marga, L.E. Niklason, G. Forgacs, Scaffold-free vascular tissue engineering using bioprinting. Biomaterials 30(30), 5910-5917 (2009). https://doi.org/ 10.1016/j.biomaterials.2009.06.034

161. M.B. Chen, Engineered microvasculature platforms to study tumor-host-matrix interactions during metastatic seeding (2017).

162. J. Ahn, H. Lee, H. Kang, H. Choi, K. Son et al., Pneumatically actuated microfluidic platform for reconstituting $3 \mathrm{~d}$ vascular tissue compression. Appl. Sci. 10(6), 2027 (2020). https://doi.org/10.3390/app10062027

163. J. Lim, H. Ching, J.-K. Yoon, N.L. Jeon, Y. Kim, Microvascularized tumor organoids-on-chips: advancing preclinical drug screening with pathophysiological relevance. Nano Converg. 8(1), 1-16 (2021). https://doi.org/10.1186/ s40580-021-00261-y

164. J.M. Kelm, V. Lorber, J.G. Snedeker, D. Schmidt, A. Broggini-Tenzer et al., A novel concept for scaffold-free vessel tissue engineering: self-assembly of microtissue building blocks. J. Biotechn. 148(1), 46-55 (2010). https://doi.org/ 10.1258/rsmsmj.55.3.46

165. G.H. Lee, J.S. Lee, G.-H. Lee, W.Y. Joung, S.H. Kim et al., Networked concave microwell arrays for constructing $3 \mathrm{~d}$ cell spheroids. Biofabrication 10(1), 015001 (2017). https:// doi.org/10.1088/1758-5090/aa9876

166. J. Park, G.-H. Lee, J.Y. Park, J.C. Lee, H. Kim, Hypergravity-induced multicellular spheroid generation with different morphological patterns precisely controlled on a centrifugal microfluidic platform. Biofabrication 9(4), 045006 (2017). https://doi.org/10.1088/1758-5090/aa9472

167. M.A. Skylar-Scott, S.G. Uzel, L.L. Nam, J.H. Ahrens, R.L. Truby et al., Biomanufacturing of organ-specific tissues with high cellular density and embedded vascular channels. Sci. Adv. 5(9), eaaw2459 (2019). https://doi.org/10.1126/sciadv. aaw 2459

168. P. Datta, B. Ayan, I. Ozbolat, Bioprinting for vascular and vascularized tissue biofabrication. Acta Biomater. 51, 1-20 (2017). https://doi.org/10.1016/j.actbio.2017.01.035

169. C.R. Thoma, M. Zimmermann, I. Agarkova, J.M. Kelm, W.J. Krek, $3 \mathrm{~d}$ cell culture systems modeling tumor growth determinants in cancer target discovery. Adv. Drug Delivery Rev. 69, 29-41 (2014). https://doi.org/10.1016/j.addr.2014.03.001

170. S. Ahn, H. Lee, J. Puetzer, L.J. Bonassar, G.J. Kim, Fabrication of cell-laden three-dimensional alginate-scaffolds with an aerosol cross-linking process. J. Mater. Chem. 22(36), 18735-18740 (2012). https://doi.org/10.1039/c2jm33749e

171. B. Ayan, D.N. Heo, Z. Zhang, M. Dey, A. Povilianskas et al., Aspiration-assisted bioprinting for precise positioning of biologics. Sci. Adv. 6(10), eaaw5111 (2020). https://doi.org/10. 1126/sciadv.aaw5111

172. A. Torres, S. Bidarra, M. Pinto, P. Aguiar, E. Silva et al., Guiding morphogenesis in cell-instructive microgels for therapeutic angiogenesis. Biomaterials 154, 34-47 (2018). https://doi.org/10.1016/j.biomaterials.2017.10.051

173. C. Gentile, P.A. Fleming, V. Mironov, K.M. Argraves, W.S. Argraves et al., VEGF-mediated fusion in the generation of uniluminal vascular spheroids. Dev. Dyn. 237(10), 29182925 (2008). https://doi.org/10.1002/dvdy. 21720

174. P.A. Fleming, W.S. Argraves, C. Gentile, A. Neagu, G. Forgacs et al., Fusion of uniluminal vascular spheroids: A model for assembly of blood vessels. Dev. Dyn. 239(2), 398-406 (2010). https://doi.org/10.1002/dvdy.22161

175. J.M. Kelm, V. Djonov, L.M. Ittner, D. Fluri, W. Born et al., Design of custom-shaped vascularized tissues using microtissue spheroids as minimal building units. Tissue Engin. Part C Methods 12(8), 2151-2160 (2006). https://doi.org/10.1089/ ten.2006.12.2151

176. M. Sofman, A. Brown, L.G. Griffith, P.T. Hammond, A modular polymer microbead angiogenesis scaffold to characterize the effects of adhesion ligand density on angiogenic sprouting. Biomaterials 264, 120231 (2021). https://doi.org/ 10.1016/j.biomaterials.2020.120231

177. A. Alajati, A.M. Laib, H. Weber, A.M. Boos, A. Bartol et al., Spheroid-based engineering of a human vasculature in mice. Nat. Methods 5(5), 439-445 (2008). https://doi.org/10.1038/ nmeth.1198

178. Y. Atlas, C. Gorin, A. Novais, M.F. Marchand, E. Chatzopoulou et al., Microvascular maturation by mesenchymal stem cells in vitro improves blood perfusion in implanted tissue constructs. Biomaterials 268, 120594 (2021). https://doi.org/ 10.1016/j.biomaterials.2020.120594

179. S. Pattanaik, C. Arbra, H. Bainbridge, S.G. Dennis, S.A. Fann et al., Vascular tissue engineering using scaffold-free 
prevascular endothelial-fibroblast constructs. BioResearch 8(1), 1-15 (2019). https://doi.org/10.1089/biores.2018.0039

180. K. Jakab, A. Neagu, V. Mironov, R.R. Markwald, G. Forgacs, Engineering biological structures of prescribed shape using self-assembling multicellular systems. Proc. Natl. Acad. Sci. 101(9), 2864-2869 (2004). https://doi.org/10.1073/pnas. 0400164101

181. K. Jakab, C. Norotte, B. Damon, F. Marga, A. Neagu et al., Tissue engineering by self-assembly of cells printed into topologically defined structures. Tissue Eng. Part A 14(3), 413-421 (2008). https://doi.org/10.1089/tea.2007.0173

182. N.E. Friend, A.Y. Rioja, Y.P. Kong, J.A. Beamish, X. Hong et al., Injectable pre-cultured tissue modules catalyze the formation of extensive functional microvasculature in vivo. Sci. Rep. 10(1), 1-16 (2020). https://doi.org/10.1038/ s41598-020-72576-5

183. Y. Tan, D.J. Richards, T.C. Trusk, R.P. Visconti, M.J. Yost et al., $3 \mathrm{~d}$ printing facilitated scaffold-free tissue unit fabrication. Biofabrication 6(2), 024111 (2014). https://doi.org/10. 1088/1758-5082/6/2/024111

184. C. Xu, W. Chai, Y. Huang, R.R. Markwald, Scaffold-free inkjet printing of three-dimensional zigzag cellular tubes. Biotechnol. Bioeng. 109(12), 3152-3160 (2012). https://doi. org/10.1002/bit.24591

185. X. Yang, V. Mironov, Q. Wang, Modeling fusion of cellular aggregates in biofabrication using phase field theories. J. Theor. Biol. 303, 110-118 (2012). https://doi.org/10.1016/j. jtbi.2012.03.003

186. I.T. Ozbolat, Y. Yu, Bioprinting toward organ fabrication: challenges and future trends. IEEE Trans. Biomed. Eng.
60(3), 691-699 (2013). https://doi.org/10.1109/TBME.2013. 2243912

187. A. Shafiee, M. McCune, G. Forgacs, I. Kosztin, Post-deposition bioink self-assembly: a quantitative study. Biofabrication 7(4), 045005 (2015). https://doi.org/10.1088/1758-5090/7/4/ 045005

188. A.Y. Rioja, E.L. Daley, J.C. Habif, A.J. Putnam, J.P. Stegemann, Distributed vasculogenesis from modular agarosehydroxyapatite-fibrinogen microbeads. Acta Biomater. 55, 144-152 (2017). https://doi.org/10.1016/j.actbio.2017.03.050

189. P.M. Baptista, D. Vyas, E. Moran, Z. Wang, S. Soker, in Human Liver Bioengineering Using a Whole Liver Decellularized Bioscaffold. (Springer; 2013), pp. 289-298. https:// doi.org/10.1007/978-1-62703-363-3_24

190. F. Ruedinger, A. Lavrentieva, C. Blume, I. Pepelanova, T. Scheper, biotechnology. Hydrogels for $3 \mathrm{~d}$ mammalian cell culture: A starting guide for laboratory practice. Appl. Microbiol. Biotechn. 99(2), 623-636 (2015). https://doi.org/10. 1007/s00253-014-6253-y

191. S. Hong, S.-J. Song, J.Y. Lee, H. Jang, J. Choi et al., Cellular behavior in micropatterned hydrogels by bioprinting system depended on the cell types and cellular interaction. J. Biosci. Bioeng. 116(2), 224-230 (2013). https://doi.org/10.1016/j. jbiosc.2013.02.011

192. M. Sarker, S. Naghieh, N. Sharma, L. Ning, X. Chen, Bioprinting of vascularized tissue scaffolds: Influence of biopolymer, cells, growth factors, and gene delivery. J. Healthcare Eng. 9156921 (2019). https://doi.org/10.1155/2019/9156921 